\title{
INFLUÊNCIA DA ESTIMULAÇÃO ULTRA- SÔNICA DE BAIXA INTENSIDADE NO REPARO DE OSTEOTOMIAS DE TÍBIAS COM FIXAÇÃO FLEXÍVEL
}

Fernando Augusto Jeronymo Jorge

Dissertação apresentada ao Programa de PósGraduação Interunidades em Bioengenharia Escola de Engenharia de São Carlos, Faculdade de Medicina de Ribeirão Preto e Instituto de Química de São Carlos da Universidade de São Paulo como parte dos requisitos para obtenção do título de mestre em bioengenharia.

Orientador: Dr. Orivaldo Lopes da Silva

São Carlos - SP

2004 


\section{Agradecimento Especial}

Agradeço de forma especial, meu orientador Prof. Dr. Orivaldo Lopes Silva, pelo incentivo, confiança, ensinamentos, dedicação, por sua competência e orientação na realização deste trabalho. 


\section{Dedicatória}

Aos meus avós, Jaime e Antonieta, Jacob e Maria, por acreditarem no meu potencial.

Aos Meus pais Ivan e Leni por suas orações, pelas palavras de estímulo e pelo apoio incondicional na vida, responsáveis pelo homem que me tornei.

As minhas irmãs, Carina, Cristiene e Clarissa por todo apoio e carinho durante esta jornada.

Ao Andrezão por todo esforço, amizade, atenção e ensinamentos durante toda nossa amizade.

"Quem se aceita como é, doando de si à vida o melhor que tem, caminha mais facilmente para ser feliz como espera ser."

(Chico Xavier) 


\title{
Dedicatória
}

À Paola, por estar ao meu lado incansavelmente, acreditando $e$ incentivando todos os meus projetos de vida, por deixar a vida mais alegre e carinhosa.

\begin{abstract}
"Para conquistarmos algo na vida não basta ter talento, não basta ter força, é preciso também viver um grande amor."
\end{abstract}

(Wolfgang Mozart) 


\section{Agradecimentos}

Ao Prof. Dr. José Baptista Portugal Paulin, por disponibilizar a utilização do laboratório de Bioengenharia de Ribeirão Preto.

Ao Amigo Nelson Ferreira da Silva Jr., pela inestimável cooperação em todos os momentos da realização deste trabalho.

Aos amigos da Bioengenharia pela amizade e companheirismo durante o mestrado.

Aos amigos da Uniara, em especial a Dani e Pico por toda amizade e carinho nos bons e maus momentos desta trajetória.

Aos amigos Benigno e Nicola, pela inestimável cooperação no trabalho.

Aos Funcionários dos Laboratórios de Bioengenharia pela colaboração na realização do trabalho.

À TRAUTEC ${ }^{\circledR}$ pela confecção e fornecimento das osteossínteses e materiais necessários para a realização do experimento.

À CAPES (Coordenadoria de Apoio Pessoal de Ensino Superior), pela concessão da bolsa de mestrado indispensável para a realização deste trabalho

À todos aqueles que, de alguma forma, favoreceram para que fosse possivel a realização deste trabalho.

À DEUS por mais esta conquista. 


\section{RESUMO}

JORGE, F.A.J. (2004). Influência da Estimulação Ultra-sônica de Baixa Intensidade no Reparo de Osteotomias de Tíbias com Fixação Flexível. Dissertação de Mestrado Escola de Engenharia de São Carlos/ Faculdade de Medicina de Ribeirão Preto/ Instituto de Química de São Carlos, Universidade de São Paulo.

O Ultra-som de baixa intensidade tem demonstrado ser um recurso acelerador do processo de consolidação óssea em fraturas. Este estudo experimental investigou a influência da estimulação ultra-sônica de baixa intensidade no processo de reparo ósseo em fraturas de tíbias tratadas por meio de fixação flexível. O estudo foi desenvolvido no laboratório de Bioengenharia da FMRP da Universidade de São Paulo Campus de Ribeirão Preto, utilizando 20 coelhos machos adolescentes da raça Nova Zelândia, que foram submetidos a uma osteotomia no terço médio da tíbia e tratados com fixador externo unilateral. Após o procedimento cirúrgico os animais foram divididos em três grupos: Controle com $n=7$ (membro contralateral, não fixado), grupo controle lesão com $n=7$ (fixados e mantidos em gaiolas) e grupo ultra-som com $n=7$, que recebeu estimulação com equipamento de ultra-som de baixa intensidade $\left(30 \mathrm{~mW} / \mathrm{cm}^{2}\right)$ e ciclo de trabalho de $1 / 5$. No final de 20 dias de tratamento suas tíbias foram retiradas e submetidas a ensaio mecânico de torção. Na avaliação das propriedades mecânicas torque máximo e rigidez, não foi observada diferença significativa $(p \leq 0,05)$ entre os grupos estimulados e controle lesão. Estes resultados sugerem que a estimulação ultrasônica de baixa intensidade aplicada ao reparo de fraturas na presença de fixação flexível não influência a velocidade e o padrão de consolidação da fratura.

Palavras-chave: tecido ósseo, fratura, fixador externo, ultra-som de baixa intensidade. 


\section{ABSTRACT}

JORGE, F.A.J. (2004). The Influence of Low- intensity Ultrasound on the Tibia Osteomy Healing of Rabbits, with Flexible Fixation. Monography of Masters - Escola de Engenharia de São Carlos/Faculdade de Medicina de Ribeirão Preto/Instituto de Quimica de São Carlos. Universidade de São Paulo.

The Low-intensity ultrasound has demonstrated to be an accelerator device on the process of recovering of bone fractures. This experimental study investigated the influence of the low-intensity ultrasound stimulation on the process of bone repairing of fractures of tibia treated with flexible fixator. The study was developed at the FMRP Bioengineering laboratory, of the University of Sao Paulo, campus of Ribeirao Preto, using 20 teenager male rabbits from the New Zealand breed which were subjected to an osteomy in the median third of the tibia and treated with an unilateral external fixator. After the surgical procedure the animals were divided into three groups: Control with $\mathrm{n}$ $=7$ (paw contralateral, not fixed), group control injury with $\mathrm{n}=7$ (fixed and kept in cages) and group ultrasound with $n=7$, that received stimulation with low-intensity ultrasound equipment $\left(30 \mathrm{~mW} / \mathrm{cm}^{2}\right)$ and duty cycle $1 / 5$. At the end of 20 days of treatment, their tibia were removed and subjected to a mechanical twist test. At the evaluation of the mechanical properties: maximum torque and hardness, it was not observed significant differences $(\mathrm{p} \leq 0,05)$ among the stimulated groups and the control injury. These outcomes suggest that the low-intensity ultrasound applied for fractures healing in the presence of flexible fixation does not have influence on the velocity nor the standard of the fracture recovering.

Keywords: bone tissue; fracture; external fixator; low-intensity ultrasound. 


\section{LISTA DE FIGURAS}

Figura 1 - Estrutura Óssea : Osso Compacto (1) Osso Trabecular (2)........................... 16

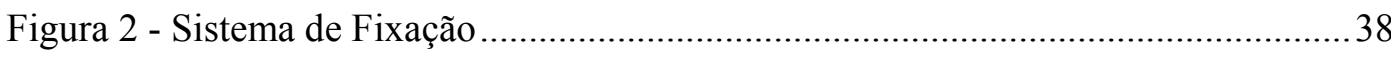

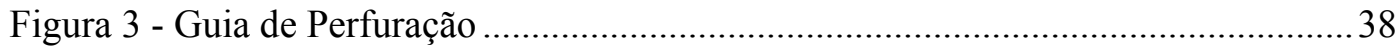

Figura 4 - Disposição do sistema de fixação........................................................................ 40

Figura 5 - Máquina de Ensaio Mecânico EMIC® preparada para o ensaio de torção: (A) Acessório adaptado; (B) Cabo de aço; (C) Travessão ..................................... 42

Figura 6 - Representação Esquemática do Acessório. (A) Plataforma Metálica; (B)

Bloco Fixo; (C) Bloco Móvel ....................................................................... 43

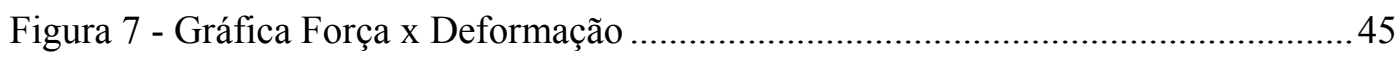

Figura 8 - Comparação entre os valores médios do torque nos três grupos experimentais.

Figura 9 - Comparação entre os valores médios da rigidez dos três grupos experimentais 


\section{LISTA DE TABELAS}

Tabela 1 - Valores individuais, média e desvio padrão do Torque Máximo de cada

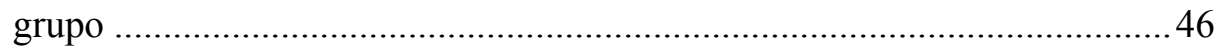

Tabela 2 - Valores individuais, média e desvio padrão da rigidez dos três grupos

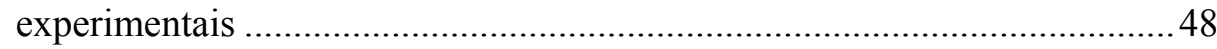




\section{SUMÁRIO}

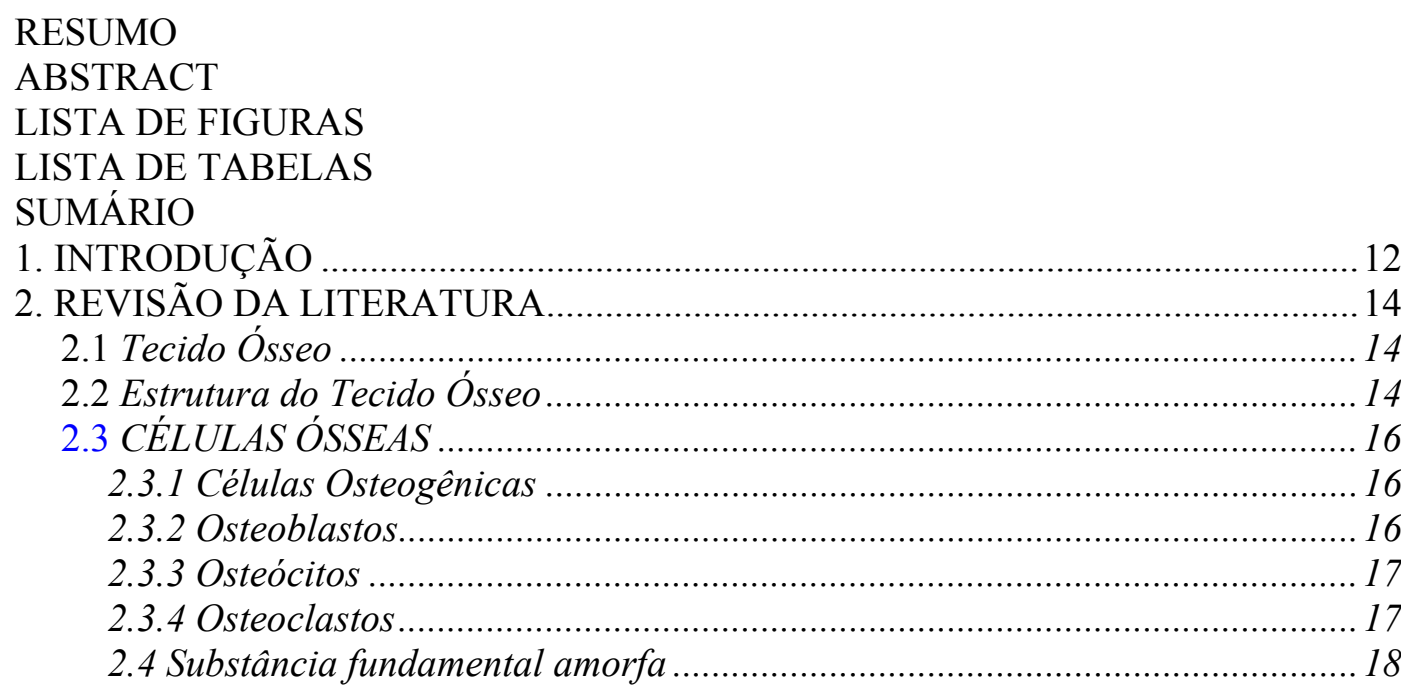

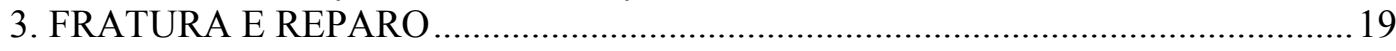

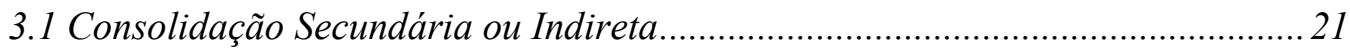

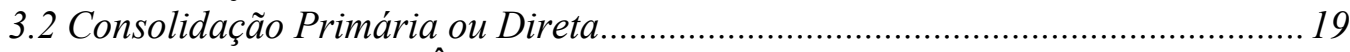

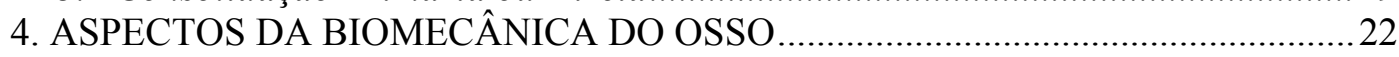

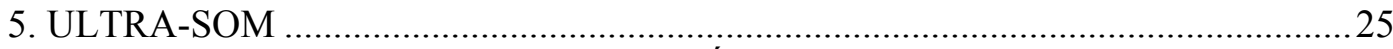

5.1 Estimulação Ultra-Sônica e Reparo Ósseo..........................................................2. 26

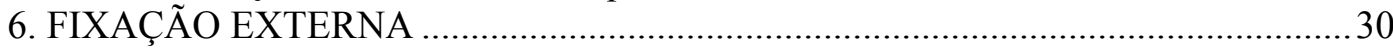

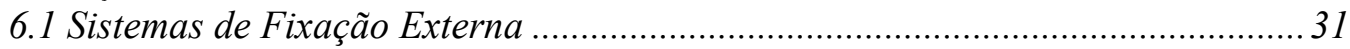

6.2 Indicações e contra-indicações para o uso de Fixação Externa e Consolidação

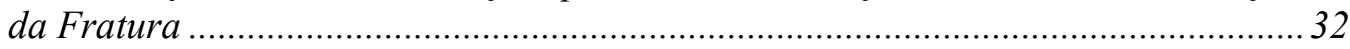

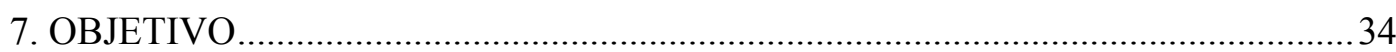

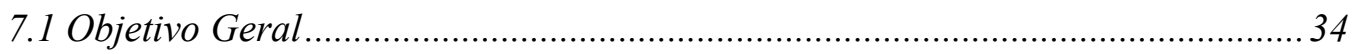

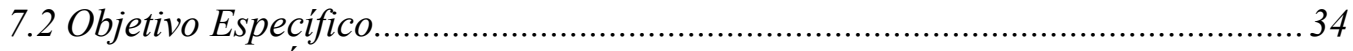

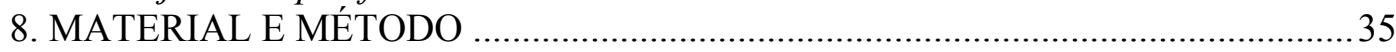

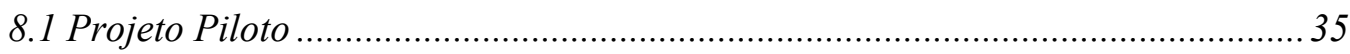

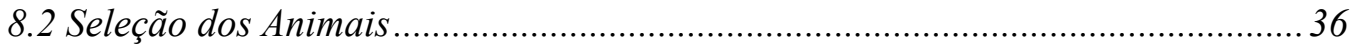

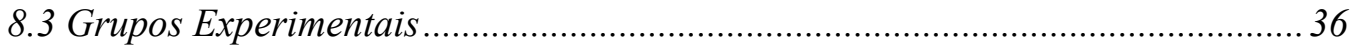

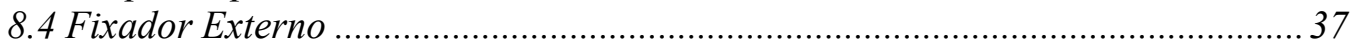

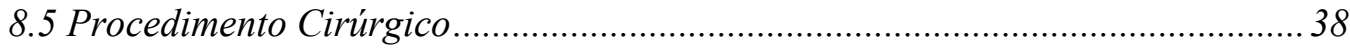

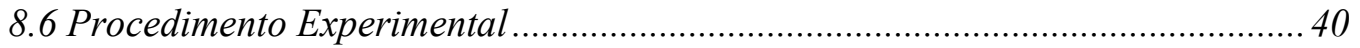

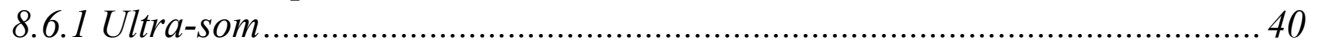

8.6.2 Aplicação do Ultra-som............................................................................ 41

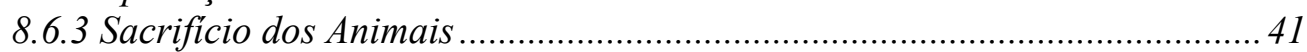

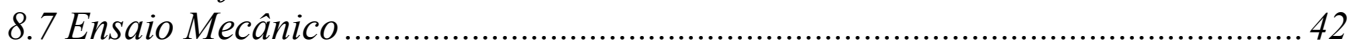

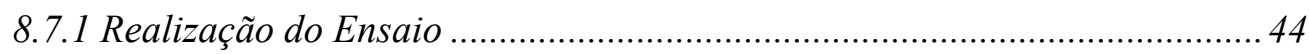

8.7.2 Obtenção das Propriedades Mecânicas .................................................... 44

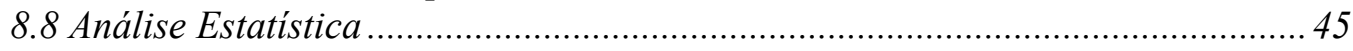

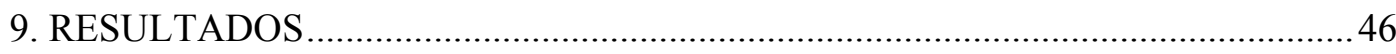

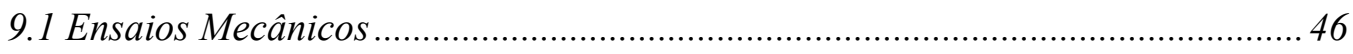

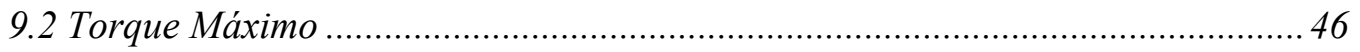




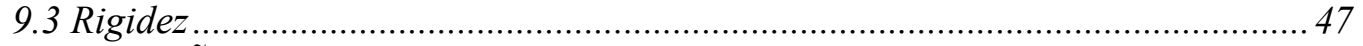

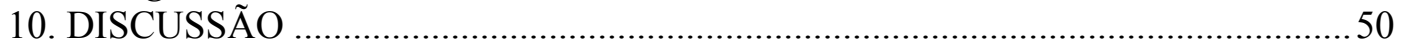

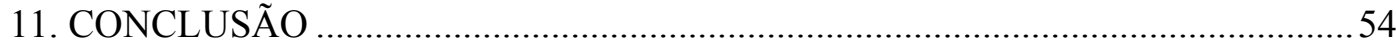

REFERÊNCIA BIBLIOGRÁFICA 


\section{INTRODUÇÃO}

Proporcionar ao homem uma boa qualidade de vida, eliminando ou minimizando ao máximo fatores e situações que atrapalhem os aspectos social, mental e físico é a principal finalidade de grande parte das pesquisas científicas.

Desta forma, muito tem sido pesquisado no sentido de manter o homem o mais próximo possível do seu estado de saúde perfeita, podendo usufruir o máximo de suas capacidades física e mental.

Nesse sentido, situações que afastem o homem, mesmo que por uma incapacidade momentânea, do seu convívio social, principalmente do seu trabalho, tem sido estudadas no sentido de reduzir ao máximo o tempo para sua reabilitação e retorno à função normal ou o mais próximo possível.

É o caso onde ocorre a perda da continuidade óssea por fratura ou procedimento cirúrgico, no qual uma série de fatores fisiológicos que visam a recuperação da funcionalidade do aparelho locomotor são desencadeados. Este processo é marcado por uma série de eventos vasculares e celulares que, na maior parte das vezes, culmina na recuperação completa da estrutura tecidual (JUNQUEIRA \& CARNEIRO, 1995; RUEDI \& MURPHY, 2000).

Este processo biológico de reparo ósseo pode ocorrer lentamente (retardo de consolidação) ou até não se desenvolver (pseudoartrose), resultando em deficiência ou incapacidade aos indivíduos.

Por isso, muito se tem investido no sentido de descobrir um método, clínico ou terapêutico, eficaz na tentativa de acelerar o processo de reparo de fraturas e, consequentemente, diminuir a probabilidade de instalação de retardos de consolidação e/ou pseudoartroses (RAMOS et al., 2000). 
A fixação externa tornou-se uma parte integrante da cirurgia ortopédica moderna, sendo crescente na prática clínica a sua utilização como um dispositivo para estabilização de osteotomias, assim como, para o tratamento de fraturas e pseudoartroses. (PACCOLA et al.,1985; CRENSHAW, 1996; RAMOS et al., 2000).

Os fixadores externos são indicados para casos de emergência onde há necessidade de imobilização imediata do paciente e a fixação interna não pode ser instituída de início, devido a lesões de partes moles associadas ou por difículdade de ordem técnica do cirurgião visando uma rápida estabilização diminuindo assim a morbidade e mortalidade. Quando utilizado como um método de estabilização temporária, foi comprovado gerar uma recuperação mais rápida das lesões de partes moles e maior facilidade na seqüência do tratamento das fraturas. A sua utilização durante todo o período biológico de reparo, pode desencadear complicações decorrentes do seu uso prolongado, tais como afrouxamento e quebra dos pinos, desvios, consolidação viciosa, retardos de consolidação e até mesmo falta de consolidação, este último sendo o principal problema (RAMOS et al., 2000; REIS., 2000).

Uma possibilidade encontrada, e que tem conquistado uma credibilidade cada vez maior da comunidade médica e científica, é a utilização sinérgica de recursos bioestimulantes na tentativa de acelerar o reparo, diminuindo a probabilidade de complicações no processo de recuperação completa da estrutura tecidual.

Entre eles, pode-se citar a utilização da radiação laser de baixa intensidade (TRELLAES, et al., 1990; BARUSHKA et al., 1995; AMARAL et al, 2001), campos eletromagnéticos (BRINGHTON \& McCLUSKY, 1988; CANE et al., 1993), correntes elétricas (BRINGHTON, 1984) e ondas ultra-sônicas (DUARTE, 1977, 1983; PILLA et al., 1991; WANG et al., 1994; TANZER et al., 1996). 


\section{REVISÃO DA LITERATURA}

\subsection{Tecido Ósseo}

O tecido ósseo é um tecido conectivo dinâmico, responsável por duas funções primordiais: promover a integridade mecânica para locomoção, atividades funcionais e a proteção de órgãos vitais; e participa da homeostasia mineral associada aos mecanismos ósseos metabólicos (EINHORN,1995). Ele é composto por uma matriz extracelular mineralizada e por células responsáveis pelo metabolismo dessa matriz (WOOLF \& DIXON,1988; EINHORN, 1995; MARCUS, FELDMAN \& KELSEY, 1995; DIO et al., 1996).

\subsection{Estrutura do Tecido Ósseo}

Os ossos, quaisquer sejam suas formas, são constituídos por duas formas diferentes de tecido: tecido compacto (cortical) e, por osso esponjoso (trabecular).

Representando $80 \%$ da massa óssea, o osso cortical, predomina nos ossos longos e nas extremidades do esqueleto apendicular, e devido ao fato do mesmo apresentar uma menor área de superfície em comparação com o osso trabecular, somente $20 \%$ da atividade metabólica ocorre no osso cortical, (ERIKSEN et al, 1993).

O osso cortical é composto por lamelas organizadas concentricamente ao redor de pequenos canais centrais que contém vasos sangüíneos. O conjunto destas lamelas concêntricas e os canais forma o Sistema Haversiano ou ósteon. Entre as lamelas, formam-se lacunas onde se alojam os osteócitos (WOOLF \& DIXON, 1988).

Internamente, revestindo o canal medular, há uma membrana chamada de endósteo. O endósteo apresenta uma pronunciada atividade celular provavelmente 
devido às forças de flexão e de tração que existem no local e é a membrana responsável pelo processo de modelamento e remodelamento ósseo.

Externamente, o osso cortical é revestido por uma membrana chamada de periósteo, composta por duas camadas. A camada externa, que é fibrosa e está em contato direto com os músculos e outros tecidos moles e possui células diferenciadas. A camada interna, que possui células osteoprogenitoras indiferenciadas de condrócitos e osteoblastos (EINHORN,1995) e contribui para a formação do calo ósseo durante o reparo de fraturas (ANDERSON \& MORRIS, 1993). O periósteo, por ser uma estrutura sólida, se encontra usualmente sujeito às forças de flexão e torção, assim como, cargas de compressão (ERIKSEN et al., 1993).

A parte representada por osso esponjoso representa $20 \%$ da massa óssea total e constitui a parte metabolicamente mais ativa do esqueleto, superior ao osso cortical (WOOLF \& DIXON, 1988), e é composta por uma malha de trabéculas ósseas dispostas tridimensionalmente ao longo das linhas de estresse do osso, sendo designado para resistir mais às forças de compressão (EINHORN, 1995).

Microscopicamente, o tecido ósseo é constituído por células e por matriz extracelular, esta dividida em orgânica e inorgânica. A região inorgânica representa $70 \%$ do peso ósseo seco e é composta $95 \%$ pelos cristais de hidroxiapatita. A região orgânica da matriz extracelular representa $23 \%$ do osso, onde $90 \%$ é composta por colágeno tipo I e os $10 \%$ restante compreendem proteoglicanas de baixo peso molecular e proteínas não colágenas. Entre elas, a osteocalcina (proteína Gla), específica do tecido ósseo e sintetizadas pelos osteoblastos, onde sua concentração reflete a formação óssea; osteopontina, uma sialoproteína envolvida na mediação da aderência celular e osteonectina, uma glicoproteína fosforilada e recebe este nome por ligar o mineral ao 
colágeno. O restante dos $7 \%$ do peso ósseo e dividido em: $5 \%$ por água e $2 \%$ pelas células ósseas (EINHORN, 1995).

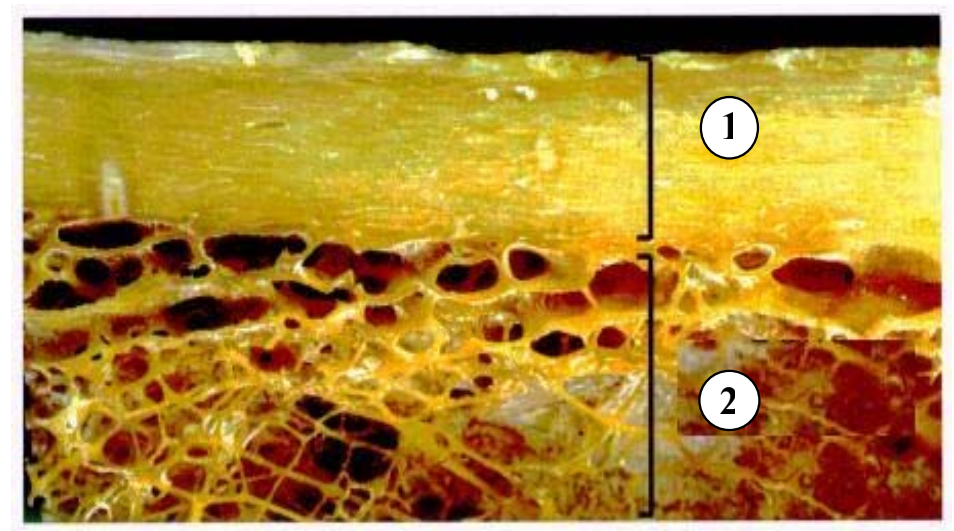

Figura 1 - Estrutura Óssea : Osso Compacto (1) Osso Trabecular (2)

\subsection{CÉLULAS ÓSSEAS}

\subsubsection{Células Osteogênicas}

São células encontradas na camada profunda do periósteo e também compreendem o endósteo. No periósteo essas células se diferenciam em osteoblastos e são responsáveis pelo crescimento do osso em espessura. No endósteo elas parecem se unir e se diferenciar em osteoclastos, sendo responsáveis pela reabsorção óssea. Essas células mantêm seu potencial de diferenciação por toda vida (EINHORN, 1995).

\subsubsection{Osteoblastos}

São células que revestem a superfície do osso em crescimento, medem de 15 a $20 \mu \mathrm{m}$, possuem um único grande núcleo e um nucléolo proeminente e tem forma cuboidal (MARTIN et al., 1993) cuja a origem é mesenquimal ( QUARLES, 1997). 
Essas células estão freqüentemente ligadas entre si por seus prolongamentos citoplasmáticos (WOOLF \& DIXON, 1988). Apresentam-se ricas de retículo endoplasmático, o que caracteriza sua capacidade de síntese protéica e matriz extracelular (MARTIN et al., 1993). Essas células tornam-se mais evidentes quando envolvidas pela matriz recém sintetizadas por eles, e uma vez enclausurados pela matriz óssea, passam a chamar "osteócitos” ( MARTIN et al., 1993).

\subsubsection{Osteócitos}

São células achatadas em forma de amêndoas que se encontram dentro de lacunas, das quais partem prolongamentos citoplasmáticos que ocupam os canalículos que permitem a sua comunicação com outros osteócitos, com osteoblastos e com células de revestimento da superfície ( ROSS, 1993; MARTIN et al., 1993 e JUNQUEIRA \& CARNEIRO, 1995). Sua função esta relacionada com a transferência de íons, principalmente de cálcio e fósforo, do interior para o exterior das unidades ósseas e daí para o líquido extracelular (MARCUS, FELDMAN e KELSEY, 1995). Recentemente, evidências têm sugerido que os osteócitos podem receber sinais mecânicos e transmitilos para outras células ósseas (MARTIN et al., 1993; EINHORN, 1995; FORWOOD et al., 1996; NOBLE \& REEVE, 2000 e CHOW, 2000), atuando desta forma no processo de remodelamento ósseo. A morte do osteócito é seguida pela absorção da matriz (ROSS \& ROMRELL, 1993; JUNQUEIRA \& CARNEIRO, 1995).

\subsubsection{Osteoclastos}

São células gigantes multinucleadas, com função de reabsorção da matriz extracelular ( BARON et al.,1993 e MARTIN et al, 1993). Este tipo de célula se encontra nas superfícies óssea, especificamente na interface entre os tecidos moles e os 
tecidos calcificados, em uma área onde a matriz óssea está totalmente mineralizada. A maior atividade reabsortiva ocorre na superfície endosteal, mesmo o periósteo fazendo parte desta interface ( BARON et al, 1993).

\subsection{Substância fundamental amorfa}

É composta pela matriz orgânica, sais inorgânicos e água.

A matriz: formada por fibras colágenas $(95 \%$ colágeno tipo I) e por uma quantidade pequena de glicoproteínas e proteoglicanas.

A parte inorgânica: $70 \%$ da matriz óssea é composta basicamente por cristais de hidroxiapatita, abundantes em cálcio e fosfato. E encontramos outros ions em menor quantidade como: potássio, bicarbonato, magnésio, sódio, citratos e fluoretos.

Água: ocupa espaço dentro dos ossos, como nos canais de Havers e dentro dos agregados moleculares das fibras colágenas (SILVA, 1987).

A característica marcante do tecido ósseo que é a rigidez e resistência são adquiridas através da associação de hidroxiapatita com as fibras colágenas. 


\section{FRATURA E REPARO}

Fratura é a interrupção da continuidade e integridade mecânica de um osso, seja ela traumática ou cirúrgica (TUREK,1991; SCHENK, 2000).

O reparo ósseo é um processo regenerativo complexo e de extrema importância a vida humana, sendo responsável pelo restabelecimento da integridade mecânica, e conseqüentemente funcional, do tecido ósseo ( HADJIARGYROU et al.,1998).

A reparação óssea e a consolidação das fraturas podem seguir dois padrões distintos: Consolidação Direta ou Primária, e Consolidação Indireta ou Secundária (SCHENK, 2000; RÜEDI \& MURPHY, 2000 )

\subsection{Consolidação Secundária ou Indireta}

Juntamente com a fratura óssea ocorre rompimento de vasos sangüíneos do próprio osso e de tecidos moles adjacentes, tendo como conseqüência imediata a formação de um coágulo na local da fratura gerado pelo extravasamento de sangue. Associado a esta lesão direta, rompimentos dos vasos sangüíneos dentro dos canais Haversianos, criam uma lesão indireta da fratura, tendo como conseqüência a interrupção do fluxo sangüíneo e morte dos osteócitos nos dois lados da linha de fratura, dando início ao processo de reparo.

Nessa fase inicial, uma reação inflamatória aguda se instala ( 3 dias pós fratura), com participação de células polimorfonucleares (neutrófilos/basófilos), macrófagos e posteriormente fibroblastos. Ocorre a remoção progressiva do coágulo através da fagocitose e inicia-se a invasão e substituição do coágulo por tecido de granulação, que a seguir diferencia-se em tecido fibroso, condral e ósseo (calo macio) (JUNQUEIRA \& CARNEIRO,1995; RÜEDI \& MURPHY, 2000). Uma nova formação 
óssea inicia-se subperiostealmente, através do espessamento do periósteo devido a proliferação ativa das células osteogênicas, assim como as células endósteas iniciam suas atividades mitóticas. Este espessamento contínuo do periósteo gera a formação de uma bainha composta por células osteogênicas ao redor de cada fragmento, semelhante a um colar. A velocidade de proliferação destas células superam a velocidade de crescimento dos capilares do periósteo, e por isso apenas as células na porção mais profunda do calo externo encomtram-se em ambiente altamente vascularizado, o que as permite diferenciar-se em osteoblastos e iniciar a deposição de matriz óssea na superfície externa dos fragmentos. Enquanto que nas partes mais superficiais isto é na região externa dos colares, praticamente avascularizada, estas células se transformam em condroblastos e condrócitos, desenvolvendo assim, a cartilagem na região (SCHENK, 2000; POLLAK et al, 2000; BELANGERO, 2000; RÜEDI \& MURPHY, $2000)$.

Posteriormente, os passos adicionais para o reparo ósseo seguem os modelos da ossificação endocondral, formando desta forma o calo rígido (RÜEDI \& MURPHY, 2000). Com a fratura apresentando uma união rígida, inicia-se o processo de remodelamento do calo ósseo, onde inicialmente o tecido ósseo morto é reabsorvido por ação osteoclastica, abrindo caminho para a ação osteoblastica e substituição de todo osso morto por osso viável, através da formação de novas trabéculas que se originam na cavidade medular e extremidades fraturadas do osso. Onde mais tarde este tecido ósseo trabecular é convertido em osso cortical denso, restabelecendo o aspecto morfológico original, incluindo a restauração do canal medular (JUNQUEIRA \& CARNEIRO,1995; SCHENK, 2000) 


\subsection{Consolidação Primária ou Direta}

Este padrão de reparo direto é caracterizado pela consolidação isenta de formação de calo ósseo, o que representa a principal diferença do mecanismo de consolidação indireta. As fraturas podem sofrer reparação direta desde que seus fragmentos sejam alinhados com exatidão e apresentem uma estabilidade absoluta.

Se comparado ao mecanismo indireto de cicatrização, este é um processo lento e característico das fraturas fixadas com dispositivos de fixação rígida como: parafusos de retardo, placa de compressão axial ou outro dispositivo de fixação interna que evite quaisquer movimentos interfragmentários. (SCHENK, 2000; POLLAK et al, 2000; BELANGERO, 2000; RÜEDI \& MURPHY, 2000 ). 


\section{ASPECTOS DA BIOMECÂNICA DO OSSO}

O comportamento biomecânico do tecido ósseo é intimamente dependente da sua massa, das propriedades mecânicas, da geometria e da arquitetura (EINHORN, 1995). O equilíbrio entre estes componentes mantém a integridade óssea para que o esqueleto possa suportar as diferentes sobrecargas durante a vida.

O colágeno ósseo é o responsável por permitir que o osso responda às sobrecargas causadas por forças de tensão, mas ao mesmo tempo, a sua composição não permite que o osso resista às forças de compressão. Esse papel é desempenhado pelos fosfatos de cálcio, que juntamente com o colágeno ósseo, formam um material resistente tanto às forças de compressão e tensão, como às forças de torção (CORNWALL, 1984).

Existem vários fatores que contribuem para a manutenção da força óssea e desta maneira garantem a integridade do esqueleto.

O estímulo mecânico tem sido apontado como sendo um ativador da osteogênese (TURNER et al., 1994; TURNER et al., 1995; FORWOOD et al., 1996; MUNDY, 1999; NOBLE \& REEVE, 2000) e geralmente é o fator primário na aquisição e manutenção da massa óssea (SOGAARD et al., 1994). Uma teoria proposta por FROST (1983) diz que uma sobrecarga mecânica que ultrapasse um limiar mínimo de força, estimula o aumento da formação óssea, sugerindo que a deformação promovida por esta força, dentro do tecido ósseo, pode ser um determinante primário de uma resposta adaptativa do tecido.

Das diversas formas físicas que influem sobre as células ósseas para induzir a osteogênese, a eletricidade tem ganho destaque. Sendo denominada como bioeletricidade, é um fator que desencadeia respostas celulares ao estímulo mecânico. Seguindo os princípios da Lei de Wolff proposta em 1892, quando um osso é submetido 
a uma sobrecarga, a tensão formada gera potenciais elétricos inicialmente na superfície do tecido. Estes potenciais são resultados da conversão da energia mecânica de deformação em energia elétrica, que é baseada no conceito de piezoeletricidade, onde os potenciais elétricos são produzidos pela deformação dos componentes orgânicos do osso (DEALER,1981; CHARMAN,1990; EINHORN,1995). Durante esta conversão de energia mecânica em potencial elétrico, a polaridade da superfície é sempre característica da deformação, havendo formação de polaridade negativa em resposta às forças de compressão e polaridade positiva em resposta às forças de tensão (CHARMAN, 1990). Há evidências de que o potencial gerado endogenamente, age como um sistema de controle para a remodelação do osso, que responde com ativação dos osteoblastos, quando são gerados potenciais negativos, e com ativação dos osteoclastos, quando são gerados potenciais positivos (CHARMAN, 1990).

Mas a forma pela qual estes processos são ativados ainda não foram claramente estabelecidos. Estudos apontam o osteócito como sendo a célula chave deste processo (TURNER et al., 1994; TURNER et al., 1995 e FORWOOD et al., 1996).

Recentemente, alguns estudos demostraram que os osteócitos podem registrar um sinal mecânico de sobrecarga e transmitir este sinal para osteócitos adjacentes (NOBLE \& REEVE, 2000). Esse sinal gera uma tensão que se propaga dentro do sistema de canalículos do tecido ósseo, tendendo a amplificar este sinal, levando a um aumento substancial da deformação das células, o que desencadeia um incremento da resposta celular (TURNER et al., 1995). Estas células agiriam como mensageiro elétrico primário do tecido ósseo (CHARMAN, 1990).

Muitos pesquisadores sugerem que os osteócitos produzem um sinal proporcional ao estímulo mecânico de sobrecarga, recebido em seus sensores de superfície. Esse estímulo chega até os osteoblastos e células de revestimento ósseo 
através dos prolongamentos citoplasmáticos dos osteócitos e também através das junções intercelulares. Juntamente com estas observações, alguns autores têm defendido a hipótese de que os osteoblastos quiescentes, conhecidos como células de revestimento ósseo, são responsáveis por ativar as unidades metabólicas básicas (UMBs) para remodelar o osso em resposta aos sinais provenientes dos osteócitos (MARTIN, 2000).

Alguns trabalhos têm sido desenvolvidos com o objetivo de melhor elucidar a questão da resposta mecanobiológica do tecido ósseo. Associando o conhecimento da piezoeletricidade ao conhecimento da propagação de ondas mecânicas em materiais biológicos, DUARTE (1977) desenvolveu uma técnica de estimulação ultra sônica visando acelerar a reparação de fraturas.

O método ultra-sônico, que não é invasivo, vem sendo utilizado clinicamente desde 1979, com resultados positivos na consolidação de fraturas com retardo ou pseudoartroses, demostrando também resultados na redução do tempo de consolidação de fraturas recentes (PILLA et al, 1991). 


\section{ULTRA-SOM}

O ultra-som pode ser definido como uma forma de energia mecânica, que se propaga por ondas acústicas com uma freqüência mais elevado do que o limite audível humano, isto é acima de $20 \mathrm{kHz}$. As ondas ultra-sônicas são geradas por transdutores ultra-sônicos, também chamados simplesmente de transdutores. De um modo geral, um transdutor é um dispositivo que converte um tipo de energia em outro. Os transdutores ultra-sônicos convertem energia elétrica em energia mecânica e vice-versa.. Existem transdutores naturais, como quartzo e a turmalina, mas hoje são utilizados cristais cerâmicos sintéticos, como o sulfato de lítio, fosfato dihidratado de amônia e o Titanato zirconato de chumbo (PZT), sendo este o mais utilizado por ser mais eficiente e durável. O cristal, para ser usado como transdutor, deve ser cortado de forma que um campo elétrico alternado, quando nele aplicado, produza variações em sua espessura. Dessa variação resulta um movimento nas faces do cristal, originando as ondas sonoras. Onda é uma perturbação ou distúrbio (vibrações) que são transmitidas através do vácuo ou de um meio gasoso, líquido ou sólido. Sabemos que existe uma variedade muito grande de ondas; por exemplo, as ondas do mar, as ondas em uma corda, numa mola, as ondas sonoras e as ondas eletromagnéticas, entre outras. Essas ondas podem diferir em muitos aspectos, mas todas podem transmitir energia de um ponto a outro.

O ultra-som quando atravessa um tecido tem sua intensidade e amplitude diminuída de acordo com a distância percorrida pelas ondas acústicas, sendo esta característica do U.S. conhecida como Atenuação e podendo ocorrer de duas formas: Absorção, que é a conversão da energia vibracional (mecânica) absorvida pelo tecido em energia molecular ou em movimentos moleculares aleatórios, resultando em calor, o que pode levar ao aumento de temperatura local; e espalhamento, isto é, o 
redirecionamento da energia propagada (reflexão). Freqüências mais elevadas são atenuadas mais rapidamente que freqüências mais baixas. Através da irradiação ultrasônica, mudanças de pressão local ocorrem, podendo causar a expansão e/ou compressão em pequenas bolhas gasosas que podem estar presentes no sangue ou em fluídos dos tecidos, provocando assim a chamada cavitação. Quando não se tem uma oscilação intensa e a movimentação no volume das bolhas não é intenso, tem-se uma cavitação estável; no caso de uma movimentação no volume intensa, isto é, uma oscilação violenta, elas podem colapsar resultando em uma cavitação instável ou chamada de cavitação transiente. Os dois tipos de cavitação geram um microfluxo acústico no fluido ao redor da bolha oscilante, sendo chamado de micro fluxo. Esse microfluxo pode levar a alguns benefícios da estimulação ultra-sônica (TEER HAAR, 1987; DYSON, 1987).

\subsection{Estimulação Ultra-Sônica e Reparo Ósseo}

A utilização do ultra-som na medicina vem ocorrendo a anos e apresenta diversas aplicações, incluindo procedimentos diagnósticos (intensidades muito baixas de 1 a $50 \mathrm{~mW} / \mathrm{cm}^{2}$ ), cirúrgicos (intensidades elevadas de 5 a $300 \mathrm{~W} / \mathrm{cm}^{2}$ ) e terapêuticos (intensidades médias de 0,5 a 3 W/cm²) (ZISKIN,1989; HECKMAN et al,1994).

Além da finalidade de diagnóstico, o ultra-som de baixa intensidade é usado como um recurso terapêutico para estimular a osteogênese e tem como base fisiológica as propriedades biomecânicas do osso (KRISTIANSEN et al, 1997; NARUSE et al, 2000).

Relacionada ao reparo ósseo a estimulação ultra-sônica transmite forças micromecânicas e tensão ao local da fratura e com isso promove a formação óssea de uma maneira comparada ao postulado pela lei de Wolff. A hipótese mais aceita é a de 
que as vibrações do U.S de baixa intensidade estimulem o efeito piezoelétrico do osso e que a corrente elétrica resultante intensifique o processo de reparo (DUARTE, C. R.,1977;DUARTE,C.R.,1983; TAVAROLI,1982 ; EVANS 1982).

A formação de cargas elétricas na superfície celular, devido à aplicação de estimulação elétrica, gera uma alteração nos potenciais de membrana dos osteoblastos o que permite a eles uma maior captação de nutrientes e bombeamento de ions. As células então atuam como um transdutor biológico, onde uma atividade mitótica aumentada é produzida pela estimulação elétrica (BASSET, 1965).

Dando início ao estudo do ultra-som pulsado de baixa intensidade como um estimulador osteogênico, DUARTE (1977, 1983), baseado na piezoeletricidade do tecido ósseo, investigou o efeito da estimulação ultra-sônica de baixa intensidade na consolidação de fraturas ósseas experimentais, produzindo osteotomias em fíbulas e em fêmures de coelhos, estimulando durante 4 a 18 dias, por 15 minutos diários, observou, através de análises radiográficas e histológicas (análises qualitativas e análise quantitativa através da medida da área do calo formado), uma significativa aceleração no processo de regeneração do tecido ósseo com um ganho de tempo na consolidação de fraturas de coelho, na ordem de $50 \%$.

Utilizando um modelo de osteotomia de fíbulas de coelhos e estimulação com ultra-som de baixa intensidade $\left(30 \mathrm{~mW} / \mathrm{cm}^{2}\right)$ por 20 minutos diários, PILLA e colaboradores $(1990,1991)$ demonstraram uma aceleração no processo de reparo, assim como um aumento significativo da resistência mecânica e rigidez do calo.

Pesquisas mostram que o ultra-som de baixa intensidade é capaz de promover o aumento da angiogênese na região da fratura. $O$ aumento da vascularização foi observado após o primeiro dia de tratamento e continuou significativo nas duas semanas consecutivas (RYABY et al, 1991; RAWOOL et al, 1997). Neovascularização que 
facilita a difusão de componentes essenciais, como por exemplo fatores de crescimento, para um reparo normal leva a uma diminuição no tempo de regeneração do tecido ósseo (HADJIARGYROU et al, 1997).

RYABY e colaboradores (1992) observaram que o ultra-som tem um papel na modulação da síntese de fator beta transformador do crescimento (TGF $\beta$ ), um importante fator de crescimento envolvido na formação de osso e cartilagem, afetando proliferação e diferenciação de osteoblastos e síntese de matriz óssea.

Outro estudo realizado com ultra-som de baixa intensidade $\left(30 \mathrm{~mW} / \mathrm{cm}^{2}\right)$, por 20 minutos diários, em linhagens de células osteoblásticas de ratos, demonstrou um aumento na produção de prostaglandina $\mathrm{E} 2\left(\mathrm{PGE}_{2}\right)$ e estimulou a expressão de mRNA ciclooxigenase-2, importante enzima participante do processo de produção de $\mathrm{PGE}_{2}$ (KOKUBO et al, 1999).

Foram encontrados também inúmeros estudos que mostram índices de sucesso da estimulação ultra-sônica de baixa intensidade no tratamento de, retardos de consolidação e pseudoartroses: 85\% (DUARTE et al ,1996), 83\% (STRAUSS et al, 1996), 80\% (MAYR \& RUTER, 1998).

Em um outro estudo avaliando o efeito da estimulação com ultra-som em pseudoartroses infectadas da tíbia na presença de osteossínteses, MEANI \& ROMANO (1997), relataram um índice de sucesso maior que 95\%.

Um estudo de FRANKEL (1998), relata índices de sucesso no tratamento de fraturas de fêmur, úmero, rádio, rádio/ulna, tíbia e tíbia/fíbula com retardo de consolidação variando de $82 \%$ à $97 \%$.

Sabe-se que a onda ultra-sônica de baixa intensidade tem efeito estimulante e intensificam o processo de reparo (COLOMBO et al,1991; DUARTE,1983; TAVAKOLI,1982; EVANS,1992). Mas o mecanismo pelo qual isso ocorre é ainda um 
tema que envolve muitas descobertas científicas, o que estimula a continuidade das pesquisas abordando este assunto. 


\section{FIXAÇÃO EXTERNA}

A utilização da fixação externa para o tratamento de fraturas é utilizada a mais de 130 anos, com estudos descritos por Malgaigne em 1853 e Parkhill em 1897, sendo este último considerado o precursor dos fixadores modernos (ROTBANDE \& RAMOS, 2000).

Atualmente vem ocupando destacada posição no tratamento de fraturas em pacientes politraumatizados, em que o risco de perderem o membro e até mesmo a vida é eminente, como casos de fraturas múltiplas e expostas graves, com grandes danos de tecidos moles, e em casos de falta de consolidação (RAMOS et al., 2000; POLLAK et al.,2000; BONGIOVANNI et al.,2000).

A utilização de fixadores externos apresenta algumas vantagens como: a estabilização óssea sem interferência no foco da fratura e com menos implantes, sem aumentar o dano de tecidos moles, correções no alinhamento e comprimento de uma extremidade fraturada, vigilância direta do membro e ferida, movimentação das articulações proximais e distais, mobilização precoce do paciente é permitida até com aplicação de carga no segmento e tratamentos associados a fixação (BEHRENS, 1989a; MORO, 1992; CRENSHAW, 1996; BELANGERO, 2000).

Mesmo com essas vantagens, a fixação externa apresenta também alguns problemas, como por exemplo: falhas clínicas decorrentes da má colocação dos pinos, ocasionando lesões neuro-vasculares e rigidez articular, falhas mecânicas nos componentes; falhas na manufatura do produto e falhas multifatoriais por problemas nos fios, retardo na consolidação, falta de experiência e expectativas irreais (BEHRENS 1989). 


\subsection{Sistemas de Fixação Externa}

Um aparelho de fixação externa apresenta componentes básicos como: fios ou pinos de fixação, os elementos de conexão entre os pinos ou fios à haste (clampes), e a haste conectora. O fio ou pino de fixação é o primeiro componente básico do aparelho de fixação externa, sendo o responsável por conectar o osso no restante do aparelho; os clampes são os responsáveis por conectar os pinos ou fios à haste, podendo ser clampes simples que conectam-se com pinos individuais ou clampes especializados que conectam os fios ou pinos a um anel que é secundariamente conectado a haste; as hastes são responsáveis pela conexão dos clampes ou anéis uns aos outros. Os sistemas de fixação externos podem ser de vários tipos de acordo com a disposição de seus componentes, sendo divididos em: Uniplanar (unilateral ou bilateral), Biplanar (unilateral ou bilateral) e Anelares (BEHRENS, 1989a; ROTBANDE \& RAMOS, 2000; POLLAK et al.,2000; RÜEDI \& MURPHY, 2000).

De acordo com estudos anteriores, a montagem uniplanar unilateral apresenta algumas vantagens em relação aos demais sistemas de fixação externa como por exemplo, a utilização de corredores ósseos seguros onde os fios são introduzidos de forma segura, sem afetar unidades músculo-tendíneas e estruturas neurovasculares importantes. Com uma redução de $50 \%$ de infecção no trajeto dos fios e afrouxamento dos mesmos (BEHRENS \& SEARLS, 1986; BEHRENS, 1989b; BEHRENS \& JOHNSON, 1989; POLLAK et al, 2000; BONGIOVANNI et al., 2000; BELANGERO, 2000).

Já é de conhecimento que o desempenho de qualquer sistema de fixação é dependente do tipo e direção da carga transmitida. Um fixador terá sua estabilidade mecânica máxima quando pelo menos uma de suas armações estiverem em um mesmo plano que a carga esta sendo aplicada. Na tíbia por exemplo, o carregamento fisiológico 
usualmente cria tensão de tração na face anterior da tíbia. Assim o desempenho de uma armação uniplanar/unilateral é melhor que outro tipo de armação (BEHRENS, 1989b; ONI et al.,1993 ). E por estas razões ocorreu a escolha deste sistema de fixação na realização deste estudo.

\subsection{Indicações e contra-indicações para o uso de Fixação Externa e Consolidação da Fratura}

Quando utiliza a fixação externa com o objetivo temporário de favorecer a recuperação de tecidos moles afetados pelo trauma, como em fraturas expostas, evita-se as conseqüências de seu uso prolongado, o que não é possível muitas vezes quando a fixação externa é utilizada por um tempo prolongado visando a consolidação óssea. Complicações como: infecção no trajeto dos pinos, afrouxamento e quebra, osteomielite, consolidação viciosa, retardada e falta de consolidação podem levar ao insucesso da técnica, sendo a falta de consolidação o principal problema da utilização de fixadores externos no tratamento de fraturas (BEHRENS, 1989a; BONGIOVANNI et al., 2000; POLLAK et al,2000).

Recentes pesquisas tem demostrado uma significante diminuição no tempo de tratamento com fixadores externos, em torno de 4 a 5 meses até a união e remoção do fixador (HAX et al., 1988; HEIM et al., 1990). Quando a fratura não se consolida neste período, diz-se que há um retardo na consolidação. E a ausência na união após 8 meses de tratamento é definida como pseudoartrose (MÜLLER et al., 1991). O retardo na consolidação e pseudoartrose em fraturas expostas tratadas com fixadores são freqüentes, com a literatura apresentando um alto índice de retardo de consolidação/pseudoartrose em tíbias, relacionados com a utilização de fixação externa 
(SCHODER et al., 1986; PACCOLA et al.,1985; HEIM et al., 1990; BELANGERO, 2000).

Atualmente aceita-se que a micromovimentação do foco da fratura promove estímulo à formação óssea e consolidação da fratura seguindo o modelo de consolidação secundária ou indireta de fratura. (TERJESEN, 1984; BELANGERO, 2000; OLIVEIRA FILHO, 2000). 


\section{OBJETIVO}

\subsection{Objetivo Geral}

Investigar a ação da terapia ultra-sônica de baixa intensidade no processo de reparo ósseo sob condição de fixação flexível.

\subsection{Objetivo Específico}

Investigar a influência do ultra-som pulsado de baixa intensidade nas propriedades mecânicas, torque máximo e rigidez, do tecido de reparo de osteotomias transversais de tíbia de coelhos com fixador externo uniplanar unilateral com pinos de Schanz. 


\section{MATERIAL E MÉTODO}

\subsection{Projeto Piloto}

$\mathrm{Na}$ fase inicial da pesquisa foi realizado um experimento piloto com o objetivo de selecionar o sistema de fixação a ser utilizado, onde foi avaliado as melhores dimensões quanto ao tamanho da barra de conexão e diâmetro dos pinos de Schanz a serem utilizados no trabalho.

Inicialmente foi realizado um experimento com 5 coelhos machos, adultos jovens da raça Nova Zelândia fornecidos pelo Biotério Central do Campus da Universidade de São Paulo em Ribeirão Preto com fixadores com as seguintes dimensões: barra de conexão de $10 \mathrm{~cm}$, pinos de Schanz de $2 \mathrm{~mm}$ com ausência de guia de perfuração. Foi observado durante o procedimento cirúrgico para instalação dos fixadores, com essas dimensões, fraturas no trajeto dos pinos, o que proporcionou um afrouxamento dos mesmos nos pós-operatório, assim como devido a não utilização de um guia de perfuração foi observado um posicionamento não padronizado dos pinos e conseqüente posicionamento incorreto da barra de conexão, favorecendo desta forma desvio dos fragmentos no transcorrer dos dias pós-operatórios e não consolidação.

Numa segunda fase do projeto piloto, foi realizado um experimento com 5 animais na tentativa de corrigir os problemas encontrados na primeira fase, utilizando novas dimensões; pinos de Schanz de $1 \mathrm{~mm}$, barras de conexão de $8 \mathrm{~cm}$ e um guia de perfuração confeccionado baseado nas dimensões da tíbia de um coelho com idade similar, sendo observado que os pinos de Schanz de 1mm entortavam no transcorrer dos dias pós-operatórios e o sistema de fixação perdia estabilidade e geravam um desvio e conseqüente perda do procedimento cirúrgico. 
Já numa fase final do projeto piloto foi confeccionado um sistema de fixação externa especialmente para a realização deste experimento, com as seguintes dimensões: barra de conexão de $8 \mathrm{~cm}$, pinos de Schanz de 1,5mm, com passo de 1,0 x 100mm e o guia de perfuração previamente confeccionado na etapa anterior. Foram realizados então, 10 procedimentos cirúrgicos para instalação do sistema de fixação chegando as condições experimentais pretendidas para o início do trabalho.

\subsection{Seleção dos Animais}

$\mathrm{Na}$ realização do experimento, foram utilizados 20 coelhos da raça Nova Zelândia, fornecidos pelo Biotério Central do Campus da Universidade de São Paulo em Ribeirão Preto. Todos os coelhos eram machos, adulto jovens com idade média de 3 meses, com peso corporal médio de $2800 \mathrm{~g}$. Os animais foram divididos aleatoriamente em 2 grupos: Grupo Ultra-Som (GUS) com n=10, Grupo Controle Lesão (GCL) com $\mathrm{n}=10$, distribuídos em gaiolas individuais. Todos os animais tiveram livre acesso à água e ração durante o período experimental.

O osso selecionado para a realização do experimento foi a tíbia, por apresentar fácil acesso cirúrgico, apresentando-se subcutânea no terço médio, local da osteotomia, demostrando ser um osso que melhor responde ao tratamento proposto, apresentando índices mais baixos de complicações (PACCOLA et al., 1985; CRENSHAW, 1996; ROTBANDE \& RAMOS, 2000).

\subsection{Grupos Experimentais}

Como conseqüência à morte de 6 animais, 4 animais no pós cirúrgico e 2 durante o procedimento cirúrgico, foram utilizados 14 animais estabelecidos em dois grupos experimentais $(\mathrm{n}=7)$ divididos da seguinte forma: 
a) GRUPO ULTRA-SOM (GUS): animais submetidos a osteotomia, fixados e tratados com ultra-som;

b) GRUPO CONTROLE LESÃO (GCL): animais submetidos a osteotomia, fixados e não tratados com ultra-som.

Um terceiro grupo, GRUPO CONTROLE (GC), foi formado pelas tíbias contralaterais dos coelhos do GCL.

\subsection{Fixador Externo}

O sistema de fixação utilizado foi um uniplanar unilateral, composto por: uma barra de conexão de $8 \mathrm{~cm}$, quatro pinos de Schanz de $1,5 \mathrm{~mm}$, com passo de $1,0 \mathrm{x}$ 100mm, quatro plataformas pequenas (FIGURA 2), um guia de perfuração, confeccionado baseado nas dimensões da tíbia de um coelho com idade similar ao do experimento, possibilitando direcionar e padronizar de maneira eqüidistante a perfuração e implantação dos pinos de Schanz (FIGURA 3).

Este tipo de fixador foi preferido por ser o mais usado nas indicações para fixações flexíveis ou menos rígidas de tíbias, favorecendo uma maior estabilidade do sistema (Rüedi \& Murphy, 2000; BROWNER et al.,2000), e por este ser o tipo de fixador externo utilizado pelo Departamento de Biomecânica, Medicina e Reabilitação do Aparelho Locomotor de FMRP - USP. Todo o sistema de fixação foi produzido e fornecido pela TRAUTEC® - Equipamentos Cirúrgicos de Ribeirão Preto LTDA. 


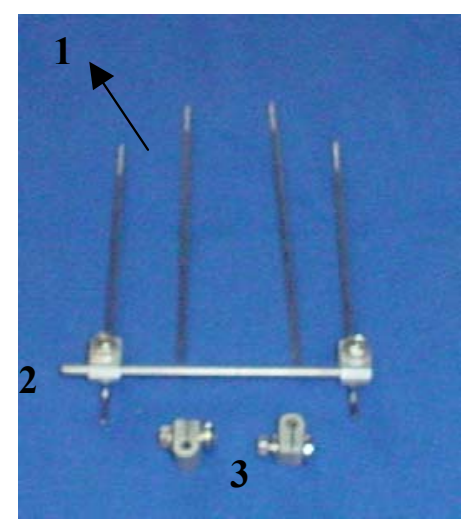

Figura 2 - Sistema de Fixação

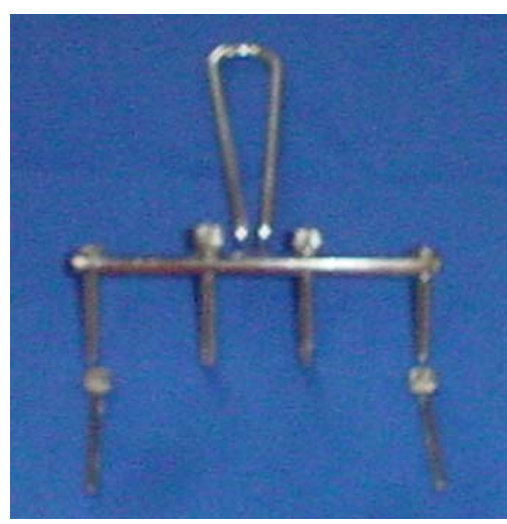

Figura 3 - Guia de Perfuração

(1-Pinos Schanz, 2- Barra, 3-Plataformas)

\subsection{Procedimento Cirúrgico}

Por um período de 24 horas antes da cirurgia os animais permaneceram em jejum, e receberam 30 minutos antes do início do procedimento cirúrgico a aplicação do anestésico Tiopental sódico, com 1g dissolvido em 40ml de soro fisiológico, na dosagem aproximada de $40 \mathrm{mg} / \mathrm{kg}$ de peso corporal, sendo injetado na veia marginal de uma das orelhas. Posteriormente foi realizado o bloqueio do nervo isquiático com Lidocaína à 40mg $/ \mathrm{kg}$. Os animais foram mantidos em posição supina e com as patas fixadas por cintas permanecendo dessa forma imobilizados durante todo o procedimento cirúrgico. Foi feita a tricotomia do membro direito submetido a cirurgia, seguida da anti-sepsia com degermante à base de iodo povidona, então o animal foi colocado na mesa cirúrgica e procedimentos cirúrgico conforme protocolo a seguir:

1. Anti-sepsia com álcool-iodado a $2 \%$, colocação de campo cirúrgico fenestrado isolando o membro.

2. Pequena incisão prévia, suficiente para a perfuração do orifício proximal com perfurador elétrico de velocidade variável e reversível, com broca de $1 \mathrm{~mm}$ de diâmetro transversalmente a metáfise proximal na sua face ântero-lateral, auxiliado pelo guia de perfuração que permitia a avaliar a posição dos orifícios em relação ao eixo da 
tíbia de tal forma que todos perfurem ambas as corticais, e o orifício distal ficasse na região supramaleolar metafísária distal.

3. Introdução do parafuso ou pino de Schanz manualmente com mandril com cabo em "T" no orifício proximal;

4. Pequena incisão na pele e perfuração do orifício mais distal;

5. colocação do pino de Schanz mais distal;

6. Pequena incisão na pele e perfuração dos dois orifícios intermediários;

7. Colocação dos dois pinos intermediários.

É de fundamental importância, para o funcionamento do mecanismo de excursão axial das hastes, que os pinos de Schanz sejam aplicados no osso, de forma a permanecerem num mesmo plano.

8. Retirada do guia de perfuração e colocação das presilhas do fixador externo, de maneira que as hastes fiquem paralelas entre si e fixadas aos pinos.

9. Incisão medial no terço médio da tíbia, longitudinal ao eixo da mesma com aproximadamente $1 \mathrm{~cm}$ de extensão;

10. Exposição do periósteo, secção do mesmo transversalmente, eqüidistante dos pinos intermediários do fixador externo;

11. Proteção das partes moles adjacentes com a utilização de afastadores;

12. Osteotomia da tíbia com utilização de uma serra oscilatória.

13. Fechamento da pele com fio de poligalactina (Vicryl $\left.{ }^{\circledR}\right)$;

14. Curativo compreensivo;

15. Remoção dos pinos de Schanz excedentes com cortador de fios de tamanho pequeno.

Após o procedimento cirúrgico, todos os animais foram imediatamente radiografados para controle pós-operatório. 
16. Aplicação, via intramuscular, de analgésico Ketoprofeno, $2 \mathrm{mg} / \mathrm{kg}$ por 4 dias e uma dose única logo após a cirurgia de Pentabiótico, $40.000 \mu \mathrm{g} / \mathrm{kg}$, antibiótico de utilização preventiva.

Após estes procedimentos os animais foram encaminhados ao biotério do laboratório de Bioengenharia da FMRP-USP, onde permaneceram em gaiolas individuais com ração e água ad libitum.

A FIGURA 4 demonstra a disposição do sistema de fixação na tíbia direita do animal.

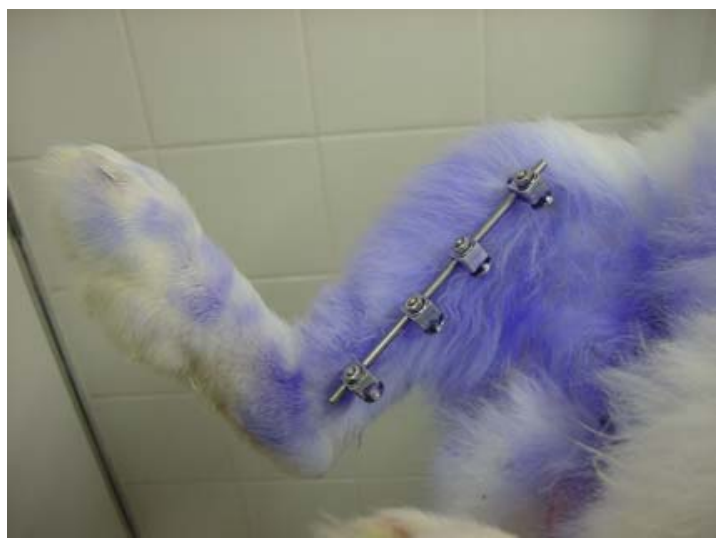

Figura 4 - Disposição do sistema de fixação

\subsection{Procedimento Experimental}

\subsubsection{Ultra-som}

Foi utilizado no presente estudo um equipamento de ultra-som pulsado de baixa intensidade, projetado e montado no laboratório da EESC/USP - campus de São Carlos, com os seguintes parâmetros:

- Freqüência de 1,5MHz;

- Ciclo de trabalho de 20\% (pulsado1/5);

- $\quad$ Intensidade de $30 \mathrm{~mW} / \mathrm{cm}^{2}$ 
Antes de iniciar as aplicações, o aparelho foi calibrado com um dosímetro de precisão (Ultra Sonic Power Meter ${ }^{\circledR}$, modelo UPM-DT-1) no laboratório de EESC/ USP -São Carlos.

\subsubsection{Aplicação do Ultra-som}

Os animais do Grupo Tratado foram submetidos a sessões diárias de aplicação de ultra-som, durante 20 minutos por 20 dias consecutivos com intervalo de 2 dias a cada 5 dias de aplicação, totalizando 4 semanas de tratamento, começando 24 horas após o procedimento cirúrgico.

Para a aplicação do ultra-som, os animais foram colocados em um dispositivo de contenção, composto por uma tábua de madeira com duas cintas de couro presas à ela, que permitiam a imobilização das cinturas escapular e pélvica do animal durante o período de estimulação.

O ultra-som foi aplicado de modo estacionário direto, usando-se gel de acoplamento para transmissão ultra-sônica. Durante todo o tratamento os animais permaneceram despertos.

\subsubsection{Sacrificio dos Animais}

Os animais foram sacrificados após 4 semanas de pós-operatório, por meio de overdose intravenosa de Tiopental sódico.

Após os sacrifícios, os membros posteriores, direito do GT e ambos os membros posteriores do GCL, foram desarticulados do joelho e tornozelo e realizada a dissecação dos tecidos moles adjacentes, isolando assim a tíbia. Essas foram embebidas em soro fisiológico e congelados à $-20^{\circ} \mathrm{C}$. 


\subsection{Ensaio Mecânico}

Foram realizados ensaios mecânicos de torção, tendo sido utilizada a máquina de ensaio EMIC® $100 \mathrm{KN}$ do Laboratório de Bioengenharia da Faculdade de Medicina de Ribeirão Preto - FMRP-USP.

A máquina possui um sistema de aquisição de dados acoplado a um microcomputador. Para o registro da carga aplicada, foi utilizada uma célula de carga com capacidade de $50 \mathrm{Kgf}$ e o registro da deformação, através de um sensor interno que registra o deslocamento do travessão da máquina de ensaio.

Por ser uma máquina especializada na realização de ensaios de tração e compressão, foi necessário adaptar um acessório que possibilitasse ao osso girar em torno de seu eixo axial principal.

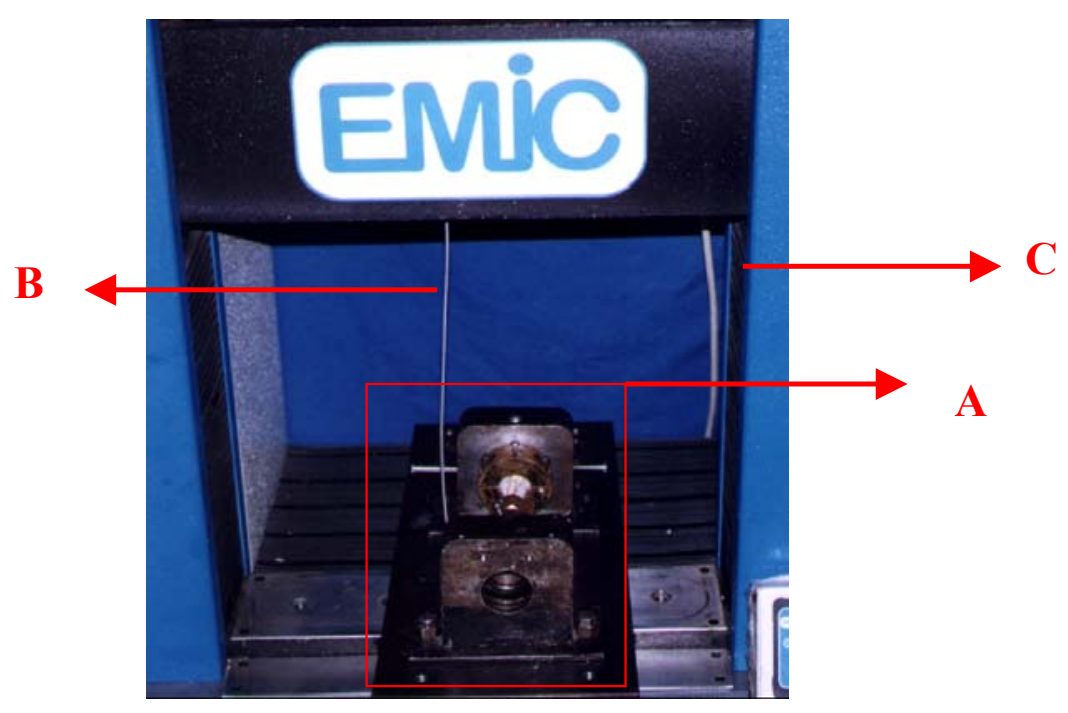

Figura 5 - Máquina de Ensaio Mecânico EMIC® preparada para o ensaio de torção: (A) Acessório adaptado; (B) Cabo de aço; (C) Travessão 
Este acessório é formado por três partes : plataforma metálica, bloco fixo e bloco móvel

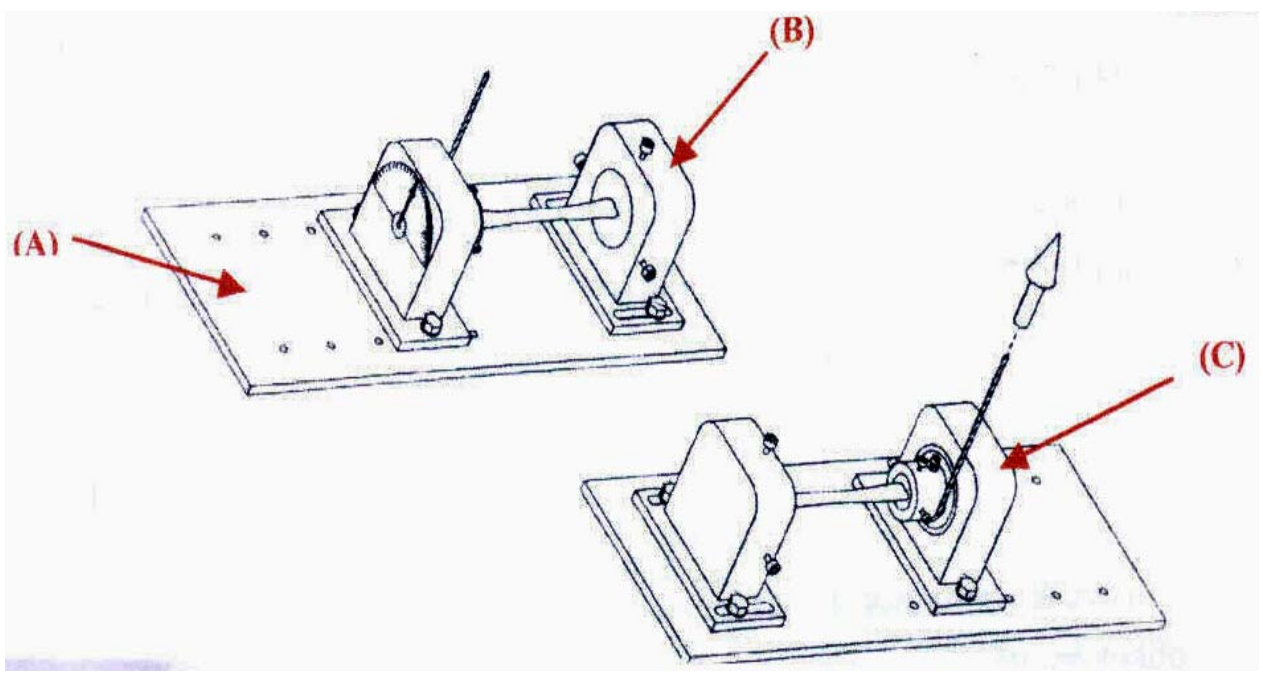

Figura 6 - Representação Esquemática do Acessório. (A) Plataforma Metálica; (B) Bloco Fixo; (C) Bloco Móvel

A. Plataforma metálica: fixada à base da máquina de ensaios, os blocos fixos e móveis são parafusados nela, com a possibilidade de ajustes longitudinais dos mesmos, de forma que ossos de diversos comprimentos podem ser ensaiados;

B. Bloco fixo: fixa à plataforma metálica, tem a função de manter imóvel uma das extremidades do osso a ser ensaiado, através de um parafuso que fixa o osso ao acessório;

C. Bloco móvel: responsável pelos ajustes longitudinais, possui um rolamento que possibilita movimentos rotacionais. A outra extremidade do osso é fixa ao centro deste rolamento através de um parafuso. Um cabo de aço flexível de $1,5 \mathrm{~mm}$ de diâmetro é preso ao eixo do rolamento e sua outra ponta na célula de carga. Enquanto a máquina realiza um movimento de tração, o cabo de aço é tracionado, gerando um movimento rotacional do rolamento em torno do seu eixo, logo uma rotação da tíbia e conseqüente realização do ensaio de torção desta tíbia. 


\subsubsection{Realização do Ensaio}

Os modelos de prova congelados foram retirados do congelador 24 horas antes dos ensaios e mantidos em um refrigerador. Os corpos de prova, 3 horas antes de serem testados, eram retirados do refrigerador e mantidos em temperatura ambiente, para entrarem em equilíbrio térmico com o meio ambiente, ainda envolvidos com gase umedecida em soro fisiológico. Os fixadores, então, eram retirados e as extremidades ósseas incluídas em resina acrílica, utilizando-se um molde cilíndrico metálico idêntico ao acessório adaptado para a máquina. No momento da inclusão das extremidades das tíbias, foram tomados cuidados quanto ao alinhamento longitudinal do eixo da tíbia.

A carga foi aplicada a uma velocidade de $10^{\circ} / \mathrm{min}$ até a ruptura do osso. Os dados eram registrados no microcomputador acoplado à máquina, através do software TESC ${ }^{\circledR}$, podendo ser analisados no próprio sistema ou extraídos.

\subsubsection{Obtenção das Propriedades Mecânicas}

As propriedades mecânicas demonstram o comportamento de um determinado material quando este recebe esforços de natureza mecânica e correspondem às propriedades que determinam a sua capacidade de resistir aos esforços aplicados, sem romper ou sem ocorrência de deformações incontroláveis (SOUZA, 1982).

Para cada ensaio, foi extraído do sistema os dados referentes a Força (N) e Deformação (mm). Pode-se, assim, construir um gráfico Força x Deformação Linear (FIGURA 7) e a partir deste gráfico calculada as propriedades mecânicas: Torque Máximo e Rigidez de cada tíbia ensaiada.

- Torque Máximo (Nm): O valor máximo para Força $(\mathrm{N})$ obtido de cada tíbia antes da ruptura, multiplicado pelo raio do eixo acoplado ao rolamento $(0,015 \mathrm{~m})$ 
- Rigidez (Nm): é obtida pela inclinação da curva de torque, no intervalo elástico, desprezada a porção relativo à acomodação da amostra.

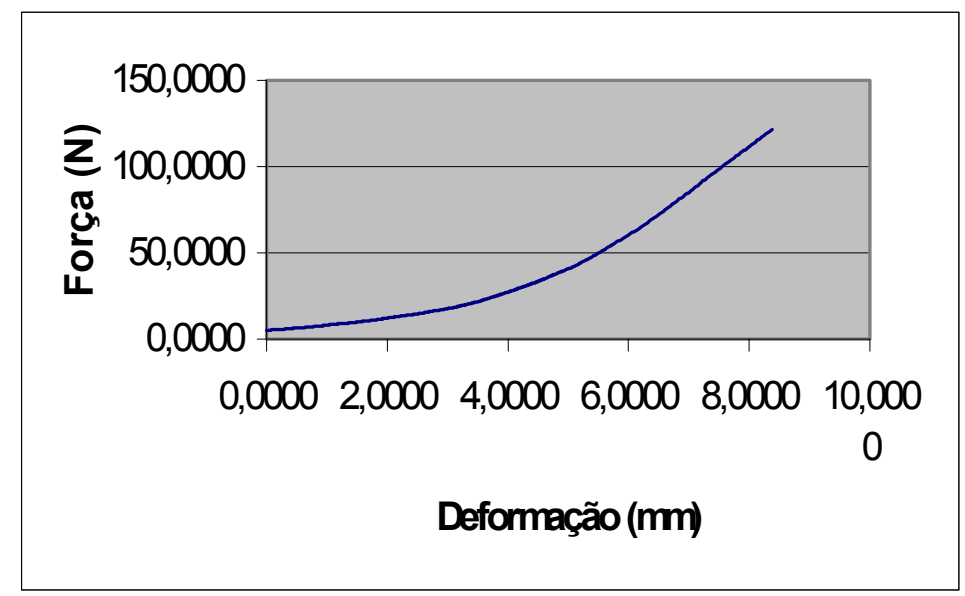

Figura 7 - Gráfica Força x Deformação

\subsection{Análise Estatística}

As propriedades mecânicas obtidas nos ensaios mecânicos foram submetidas à análise estatística, através do método ANOVA para comparação simultânea entre os três grupos, verificando a existência ou não de diferenças entre os grupos para variâncias equivalentes, e o método TUKEY para comparação entre pares de grupos. Para as análises foi utilizado o programa Graphpad Instat 3.0, com nível de significância de 5\%. 


\section{RESULTADOS}

\subsection{Ensaios Mecânicos}

Foram feitos os ensaios de 21 ossos, e os resultados dos três grupos experimentais são apresentados em conjunto com o objetivo de facilitar a comparação entre eles.

Foram obtidos através do ensaio mecânico os resultados do Torque Máximo e Rigidez de cada grupo experimental: Grupo Ultra-Som (GUS), Grupo Controle Lesão (GCL) e Grupo Controle (GC).

\subsection{Torque Máximo}

A TABELA 1 apresenta os valores do torque máximo para cada grupo, obtidos a partir da curva carga x deformação para os 7 corpos de prova de cada grupo ensaiados.

Tabela 1 - Valores individuais, média e desvio padrão do Torque Máximo de cada grupo

\begin{tabular}{cccc}
\hline Animais & $\begin{array}{c}\text { GUS } \\
\text { Torque máximo (Nm) }\end{array}$ & $\begin{array}{c}\text { GCL } \\
\text { Torque máximo (Nm) }\end{array}$ & $\begin{array}{c}\text { GC } \\
\text { Torque máximo } \\
(\mathbf{N m})\end{array}$ \\
\hline $\mathbf{1}$ & 0,95 & 1,72 & 2,14 \\
$\mathbf{2}$ & 0,95 & 1,11 & 1,95 \\
$\mathbf{3}$ & 1,39 & 0,46 & 2,13 \\
$\mathbf{4}$ & 2,18 & 1,72 & 1,61 \\
$\mathbf{5}$ & 1,14 & 1,47 & 1,33 \\
$\mathbf{6}$ & 1,05 & 0,75 & 1,24 \\
$\mathbf{7}$ & 1,14 & 1,82 & 2,12 \\
\hline Média & $\mathbf{1 , 2 6}$ & $\mathbf{1 , 2 9}$ & $\mathbf{1 , 7 9}$ \\
\hline SD & $\mathbf{0 , 4 3}$ & $\mathbf{0 , 5 3}$ & $\mathbf{0 , 3 9}$ \\
\hline
\end{tabular}


A média de Torque Máximo para o Grupo Ultra-Som foi $1,26 \pm 0,43 \mathrm{Nm}$, para o Grupo Controle Lesão foi $1,29 \pm 0,53) \mathrm{Nm}$, e para o Grupo Controle foi $1,79 \pm 0,39 \mathrm{Nm}$ (FIGURA8). Na comparação simultânea dos três grupos, não houve diferença significativa ( $p=0,76212)$. E, entre os grupos, também não houve diferença significativa [GUS x GCL (p=0,988067); GUS x GC (p=0,101221); GCL x GC (p=0,132263)].

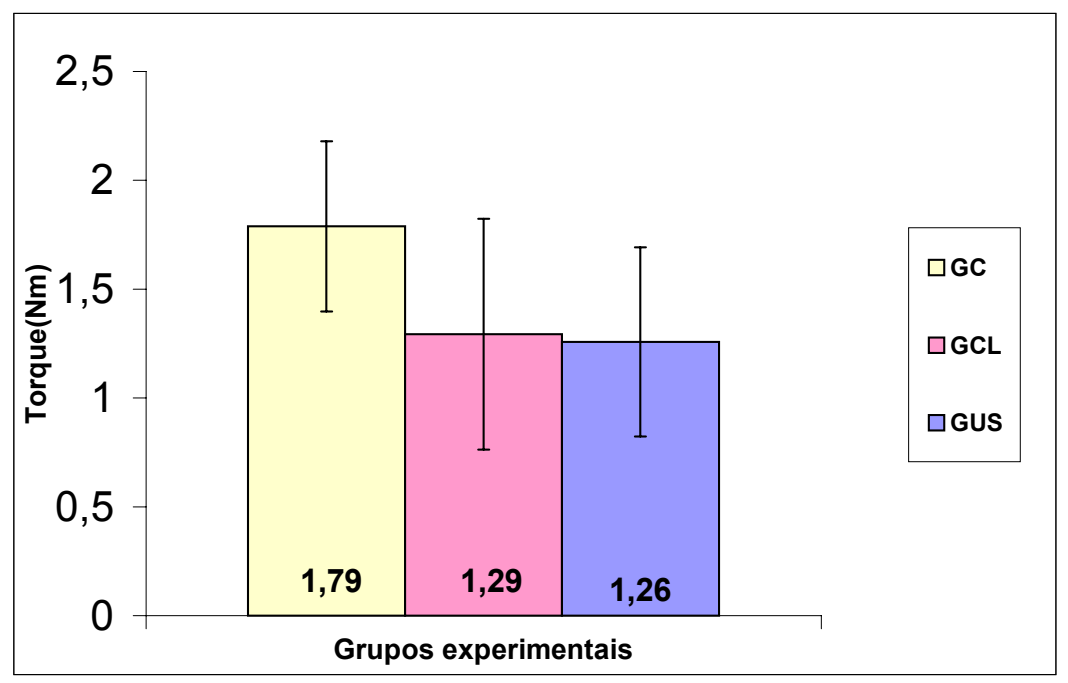

Figura 8 - Comparação entre os valores médios do torque nos três grupos experimentais.

\subsection{Rigidez}

A TABELA 2 apresenta os valores de rigidez nos três grupos experimentais, para os sete corpos de prova ensaiados. Para a obtenção dos valores médios e desvio padrão da tabela, foi aplicado aos dados originais um método de mínimos quadrados, através do cálculo do coeficiente de Pearson, considerando-se somente os pontos para os quais foi obtido $\mathrm{r}=0,7$. 
Tabela 2 - Valores individuais, média e desvio padrão da rigidez dos três grupos experimentais

\begin{tabular}{c|c|c|c}
\hline Animais & $\begin{array}{c}\text { GUS } \\
\text { Rigidez (Nm) }\end{array}$ & $\begin{array}{c}\text { GCL } \\
\text { Rigidez (Nm) }\end{array}$ & $\begin{array}{c}\text { GC } \\
\text { Rigidez (Nm) }\end{array}$ \\
\hline $\mathbf{1}$ & 0,054 & 0,055 & 0,096 \\
$\mathbf{2}$ & 0,068 & 0,073 & 0,084 \\
$\mathbf{3}$ & 0,080 & 0,064 & 0,092 \\
$\mathbf{4}$ & 0,056 & 0,100 & 0,077 \\
$\mathbf{5}$ & 0,049 & 0,099 & 0,082 \\
$\mathbf{6}$ & 0,067 & 0,090 & 0,077 \\
$\mathbf{7}$ & 0,049 & 0,066 & 0,098 \\
\hline Média & $\mathbf{0 , 0 6 0}$ & $\mathbf{0 , 0 7 8}$ & $\mathbf{0 , 0 8 6}$ \\
\hline SD & $\mathbf{0 , 0 1 1}$ & $\mathbf{0 , 0 1 7}$ & $\mathbf{0 , 0 0 8}$ \\
\hline
\end{tabular}

O valor médio da rigidez para o GUS foi $0,060 \pm 0,011 \mathrm{Nm}$, para o GCL foi de $0,078 \pm 0,017 \mathrm{Nm}$ e para o GC foi $0,086 \pm 0,008 \mathrm{Nm}$ (FIGURA 9). Pela análise estatística foi observada uma diferença significativa quando comparado simultaneamente os três grupos $(p=0,009)$. $E$, entre os grupos foi observada uma diferença significativa na comparação entre os grupos: GUS x GC ( $p=0,007)$, com o GC apresentando valores significativos maiores que o GUS, o mesmo não foi observado entre os outros grupos: GUS x GCL $(p=0,105)$ e GC x GCL $(p=0,402)$. 


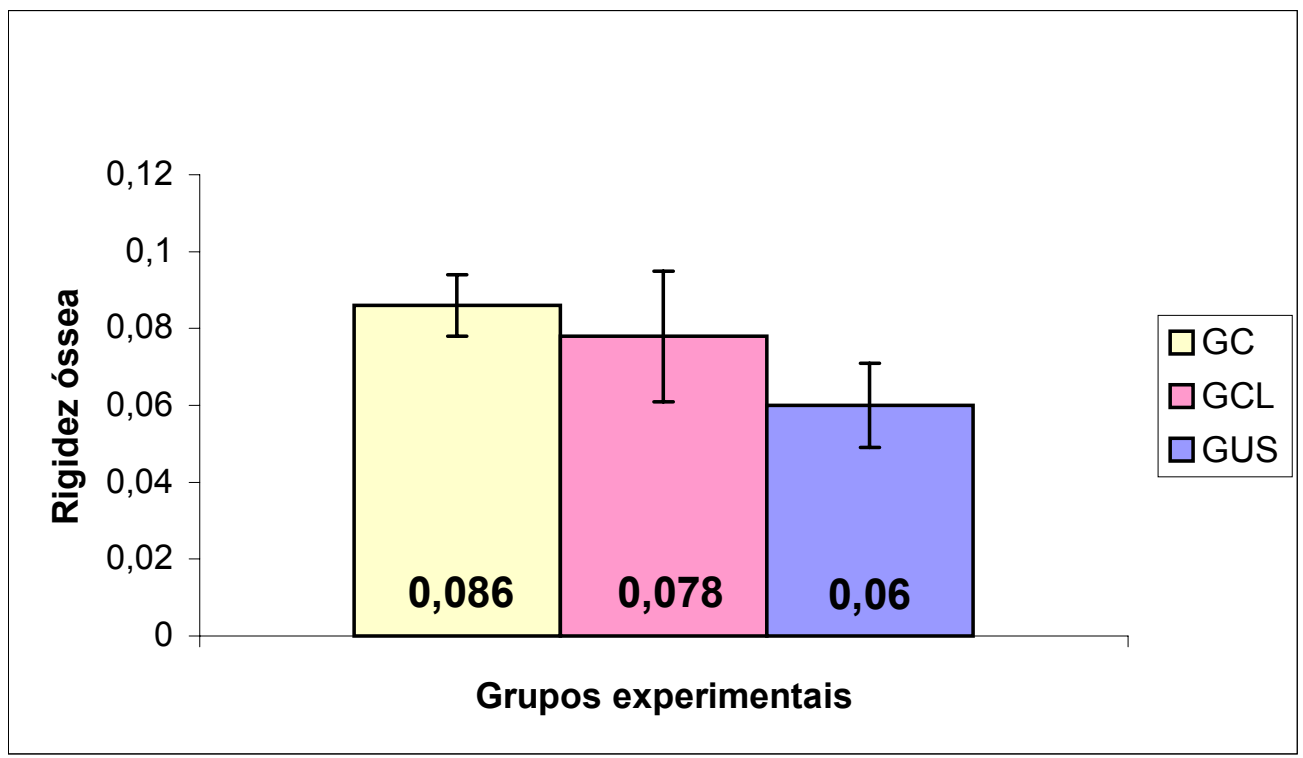

Figura 9 - Comparação entre os valores médios da rigidez dos três grupos experimentais 


\section{DISCUSSÃO}

A influência da estimulação ultra-sônica de baixa intensidade no processo de regeneração óssea de fraturas foi tema de inúmeros estudos experimentais com animais (DUARTE, 1977, 1983; PILLA et al. 1991; WANG. S.,1994; NARUSE et al, 2000).

DUARTE (1977) foi o primeiro a demonstrar em um estudo pioneiro os efeitos da estimulação ultra-sônica de baixa intensidade sobre o reparo de fraturas, evidenciando que o ultra-som de baixa intensidade provocava um aumento significativo do calo ósseo assim como uma significativa aceleração da regeneração óssea.

Em um outro estudo, utilizando valores de dosagem semelhantes aos utilizados neste estudo $\left(30 \mathrm{~mW} / \mathrm{cm}^{2}\right), 20$ min diários de aplicação, PILLA e colaboradores (1990, 1991) mostraram, a partir da análise das propriedades mecânicas obtidas por ensaio mecânico de torção, que a utilização de ultra-som de baixa em modelos de osteotomias de fíbulas de coelhos, não apenas exerceu influência positiva na quantidade de calo, como também aumentou significativamente a resistência mecânica e rigidez do calo.

WANG e colaboradores (1994), utilizando o mesmo ultra-som de baixa intensidade $\left(30 \mathrm{~mW} / \mathrm{cm}^{2}\right)$, em fratura femural em ratos, mostraram que o torque máximo médio dos ossos estimulados se apresentou $22 \%$ superior comparados ao controle. Resultados semelhantes também foram encontrados em outros dois estudos de ITO e colegas (2000) e JINGUISHI e colaboradores (1998).

Em vários outros estudos os autores relatam resultados efetivos da utilização da terapia ultra-sônica de baixa intensidade podendo diminuir o tempo de reparo ósseo e não união de fraturas (HECKMAN \& RYABY.,1994).

Nestes estudos os efeitos do ultra-som de baixa intensidade foram estudados através das propriedades biomecânicas do osso. 
No entanto, não estão bem estabelecidos os mecanismos específicos pelos quais a aplicação de uma energia ultra-sônica pode induzir a osteogênese e quais fatores extrínsecos ou intrínsecos poderiam interferir neste processo, sendo um assunto de contínua especulação científica (TAKIKAWA et al., 2001).

Vários estudos, realizados com animais e humanos, tem relatado a influência do ambiente mecânico no processo de reparo de fraturas, acelerando ou melhorando o processo de maneira significativa (O’SULLIVAN,1994; DUDA et al.,1998; PARK et al., 1998; SCHENK, 2000). Mesmo com estas afirmações, ainda não esta precisamente definido qual a real interferência do ambiente mecânico no processo de reparo de fraturas.

O presente estudo investigou a influência do uso sinérgico da estimulação ultra-sônica de baixa intensidade e dispositivos de fixação flexíveis ou menos rígidos de fratura.

Todo tratamento de uma fratura visa a sua consolidação. A utilização da fixação externa visa da mesma forma alcançar a união óssea dos fragmentos, sendo um método seguro e eficaz de obter a estabilização necessária para o reparo de uma fratura, com as vantagens de ser um sistema de simples e rápida aplicação (quando comparado com outros sistemas de fixação) pouco traumático para os tecidos adjacentes, além de permitir acesso à possíveis lesões dos tecidos moles geradas pela fratura, tendo assim um controle sobre a contaminação e a cicatrização destas lesões (BEHRENS \& SEARLS, 1986; BEHRENS, 1989b; BEHRENS \& JOHNSON, 1989; POLLAK et al, 2000; BONGIOVANNI et al, 2000).

A consolidação de uma fratura fixada com um sistema de fixação flexível ocorre pela formação de calo ósseo, seguindo os estágios de reparo por consolidação indireta ou secundária (RÚEDI \& MURPHY, 2000). Inúmeros estudos demonstram que 
múltiplos fatores relacionados ao meio ambiente mecânico do complexo "sistema de fixação / fratura", influenciam o processo de consolidação da fratura fixada, como por exemplo: suprimento sangüíneo local, precisão da restauração de comprimento e alinhamento dos fragmentos, rigidez do fixador e grau de movimentação interfragmentaria (EMAMI et al., 1995; DUDA et al., 1998; SCHENK, 2000; BELANGERO, 2000).

Numerosos estudos têm demonstrado que a rigidez do sistema de fixação influencia no tempo de reparo da fratura, sendo observado um menor tempo de consolidação em sistemas de fixação que permitem um certo grau de deformação interfragmentária (GOODSHIP \& KENWRIGHT, 1985; KENWRIGHT et al.,1989; HEIM et al., 1990). A formação de calo ósseo é amplamente influenciada pela movimentação inter-fragmentária: pequena formação de calo em fixações estáveis, e grande formação em fixações instáveis (BELANGERO, 2000).

Mesmo com evidências de que a micromovimentação entre os fragmentos ósseos pode facilitar a consolidação da fratura, o nível aceitável de micromovimentação não foi determinado e permanece em estudo (DUDA et al., 1998). Hoje estudos clínicos e experimentais que demonstraram que a fixação flexível pode gerar estímulo à formação de calo ósseo e conseqüente aceleração do reparo de fratura quando permite uma movimentação inter-fragmentaria baixa $(0,2$ a $1,0 \mathrm{~mm}$ de movimentação) (GOODSHIP et al., 1985; BONGIOVANNI et al, 2000). Entretanto, se a movimentação inter-fragmentaria for elevada e gerar uma instabilidade excessiva, a não formação de calo ósseo, retardo de consolidação e pseudoartrose podem ocorrer (KENWRIGHT \& GOODSHIP, 1989; DUDA, 1998; RUEDI \& MURPHY, 2000).

Avaliando a influência da movimentação inter-fragmentaria, KENWRIGHT \& GOODSHIP (1989), demonstraram que movimentos axiais na fratura podem inibir ou 
estimular o processo indireto de consolidação, onde amplitudes de $0,5 \mathrm{~mm}$ geraram grandes estímulos a formação de calo ósseo, enquanto amplitudes de $2,0 \mathrm{~mm}$ de movimentação axial provocaram um retardo na formação do calo ósseo e conseqüente retardo na consolidação da fratura.

De acordo com o estudo de KENWRIGHT E GOODSHIP (1989), KELLY e colaboradores (1986), deformações de 2mm são prejudiciais à consolidação, enquanto deformações de $0,5 \mathrm{~mm}$ estimulam a consolidação.

Neste estudo, os ensaios mecânicos de torção, avaliando as propriedades mecânicas média de torque máximo e rigidez, demonstraram que não há significância estatística entre grupos para ambas propriedades avaliadas. Houve significância apenas para a rigidez entre os GT e GC.

Sugere-se que os resultados obtidos podem ser decorrentes de uma movimentação inter-fragmentaria excessiva proporcionada pelo tipo de sistema de fixação utilizado neste estudo, que favorece esta movimentação (RUEDI \& MURPHY, 2000).

Foi observada também uma grande variância dos dados intra grupos na avaliação do torque máximo, sugerindo que a rigidez do sistema de fixação, que permite a movimentação inter-fragmentária, pode ter sido diferente para cada animal.

Questiona-se também qual a interferência da utilização deste tipo de fixação externa em um animal saltador e não marchador quanto aos aspectos biomecânicos do sistema e suas influências no processo de consolidação da fratura. 


\section{CONCLUSÃO}

Diante dos resultados encontrados, observou-se que a estimulação ultra-sônica de baixa intensidade não influenciou a consolidação óssea de tíbias osteotomizadas e tratadas com fixador externo unilateral ao final de 30 dias de tratamento.

Os resultados observados demonstram a necessidade de estudos, em ambiente computacional, através de aplicativos que utilizem, por exemplo, elementos finitos, para a determinação das dimensões adequadas dos componentes dos fixadores, para que seja garantida a fixação flexível dentro de limites de deformação toleráveis, ou seja, dentro de limites toleráveis da movimentação inter-fragmentária.

A taxa de sucesso observada na literatura, para aplicação de ultra-som pulsado de baixa intensidade no reparo de fraturas, com parâmetros idênticos aos utilizados no presente trabalho, indica a necessidade de experimentos futuros utilizando-se fixadores externos de dimensões otimizadas, associados à estimulação ultra-sônica. 


\section{REFERÊNCIA BIBLIOGRÁFICA}

AMARAL, A.C.; PARIZOTTO, N. A.; SALVINI, T. F.(2001). Dose-Dependency of Low-Energy HeNe Laser Effect in Regeneration of Skeletal Muscle in Mice. Laser Medicine Scienci, v. 16, p. 44-51.

ANDERSON, H. C.; MORRIS, D. C. (1993). Mineralization In: MUNDY, G. R. \& MARTIN, Physiology and pharmacology of bone. Berlin: Springer-Verlag, p. 267298.

BARON, R.; CHAKRABORTY, M.; CHATTERJEE, D.; HORNE, W.; LOMRI, A,; RAVESLOOT, J. H. (1993). Biology of the osteoclast. In: MUNDY, G. R. \& MARTIN, T. J. Physiology and pharmacology of bone. Berlin: Springer-Verlag, p.67107.

BARUSHKA, O.; YAAKOBI, T.; ORON, U. (1995). Effect of low-energy laser (He$\mathrm{Ne}$ ) irradiation on the process of bone repair in the rat tibia. Bone, v. 16, n. 1, p. 47-55.

BASSET, C. A. I. (1962). Current concepts of bone formation. J. Bone Joint Surg., v. 44, p. 496.

BEHRENS, F.(1989a). General theory and principles of external fixation. Clin. Orthop., n. 241, p. 15-23.

BEHRENS, F. (1989b). Primer of fixator devices and configurations. Clin. Orthop., n. 241, p.5-14.

BEHRENS, F.; JOHNSON. W. (1989). Unilateral external fixator. Clin. Orthop., n. 241, p. 48-56.

BEHRENS, F.; SEARLS, K. (1986). External fixation of the tibia. Basics concepts and prospective evaluation. Journal Bone Joint Surgery, 68-B(2): p. 246.

BelangerO, W. D. (2000). Princípios Gerais de Osteossíntese e Fixação Biológica das Fraturas. In: REIS, F. B. Fraturas. Cap. 3, p. 23-40.

BONGIOVANNI, J. C.; FERNANDES, H.J.A.; NETO, P.T. (2000). Uso de Fixadores Externos em Traumatologia. In: REIS, F.B. Fraturas. Cap. 7, p. 59-66.

BRINGHTON, C. T.; McCLUSKY, W. P. (1988). Response of cultured bone cells to a capacitively coupled eletric field: Inibition of AMP response to parathyroid hormone. Journal Orthop., v.6, p. 567-571.

BRINGHTON, C. T.( 1984). The semi-invasive method of treating non-union with direct current. Journal Orthop. Clin., v. 15, p. 33-45.

BURNY, F. (1972). Traitement par ostéotaxis des fratures diaphysai du tibia. Étude de 115 cas. Acta Orthop. Belg., v. 38, p. 280-301. 
CANE, V.; BOTTI, P.; SOANA, S. (1993). Pulsed magnetic fields improve osteoblast activity during the repair of na experimental osseous defect. Journal Orthop. Res., v. 11, p. 664-670.

CHARMAN, R. A. (1990). Strain generated potencials in bone and connective tissue. Physiotherapy, vol.76, n.11, p.725- 730 .

CHOW, J. W. M. (2000). Role of nitric oxide and prostaglandins in the bone formation response to mechanical loading. Exerc Sports Sci Rev, vol. 28, n. 4, p.185-188.

COLOMBO, S.J.M; DUARTE, L.R; SILVA JÚNIOR, N.F. (1991). Efeitos da variação da intensidade na consolidação ultra-sônica de fraturas experimentais. Ciência e Tecnologia, v.1 p. 73-81.

CORNWALL, M. W. (1984). Biomechanics of noncontractile tissue - A review. Physical Therapy, vol. 64, n. 12, p. 1869-1873.

CRENSHAW, A.H. (1996). Cirurgia Ortopédica de Campbell, v. 3, ed Manole, 8 ed. São Paulo.

DIO, R. D.; BARBERIO, J. C.; PRADAL, M. G.; MENEZES, A. M. S. (1996). Novos recursos para investigação de doenças ósseas. São Paulo: Criesp.

DYSON, M. (1987). Mechanisms involved in therapeutic ultrasound. Physiotherapy (UK) 73: 116-120.

DUARTE, L. R. (1977). Estimulação ultra-sônica do calo ósseo. 129p. Tese (LivreDocência) - Escola de Engenharia - São Carlos - Universidade de São Paulo - USP.

DUARTE, L. R. (1983). The stimulation of bone growth by ultrasound. Arch. Orthop. Trauma. Surgery, v.101, p.153-159.

DUARTE, L. R.; XAVIER, C. A.; CHOFFIE, M.; McCABE, J. M. (1996). Review of nonunions treated by pulsed low-intensity ultrasound. Société Internationale de Chirurgie Orthopedique et de traumatologie (SICOT), P2.110:PDS80.

DUDA, G. N.; ECKERT-HUBNER, K.; SOKIRANSKI, R.; KREUTNER, a; MILLER, R.; CLAES, L. (1998). Analysis of inter-fragmentary movement as a function of musculoskeletal loading conditions in sheep. J. Biomech. 31(3): 201-210.

EINHORN, T. A. (1995). Current concepts review enhancement of fracture healing. Journal Bone Joint Surgery 77 A(6), p. 940-956.

ERIKSEN, E. F.; VESTERBY, A.; KASSEN, M.; MELSEN, F.; MOSEKILDE, L. (1993). Bone remodeling and bone structure. In: MUNDY, G. R. \& MARTIN, T. J. Physiology and pharmacology of bone. Berlin: Springer-Verlag, p.67-107.

EVANS, F. G. (1982). Bone and ones. Journal of Biomechanics Eng., v. 104, p. 1-5. 
FORWOOD, M. R.; OWAN, I.; TAKANO, Y.; TURNER, C. H. (1996). Increased bone formation in rat tíbia after a single short period of dynamic load in vivo. Am $\mathbf{J}$ Physiol 270 (Endocrinol Metabol. 33): E419-E423.

FRANKEL, V. H. (1998). Results of prescription use of pulse ultrasound therapy in fracture management, Surgical Technology International VII (Orthopaedic Surgery), p. 389-393.

FROST, H, M. (1983). A determination of bone architecture. The minimum effective strain. Clin Orthop, v. 200, p. 198-225.

GOODSHIP, A. E; KENWRIGHT, J. (1985). The influence of induced micromovement upon the healing of experimental tibial fractures. J. Bone Joint Surg. 67B: 650-655.

HADJIARGYROU, M. et al. (1998). Enhancement of fracture healing by low-intensity ultrasound. Clinical Orthop., suplemento 355, S216- 229, out.

HAX, P. M; HIERHOLZER, G; THERMANN, R. (1988). Vorteile des unilateralen Rohrfixateur Externe bei der Stabilisierung offener Unterschenkelfrakturen. Heft zur UnfallheilkUnde, n. 200, p.293-4.

HECKMAN, J. D; RYABY, J.P. (1994). Acceleration of tibial fracture-healing by noninvasive, Low-intensity Pulsed ultrasound. J. Bone Joint Surg., v. 76, p. 26-34.

HEIM, D. et al. (1990). Der Fixateur Externe als primäre definitive Behandlung der Untersche Kelfractur mit schwere Weichteilschaden. Helv. Chir. Acta, n. 57 , p. 83946.

HERBERT, S. (1998). Ortopedia e Traumatologia: princípios e prática. 2 ed., Porto Alegre Artmed.

HOLLINGER, J.O.; BUCK, D.C.; BRUDER, S.P. (1999). Biology of Bone Healing: Its Impact on Clinical Therapy. In: LYNCH, S.E.; GENCO, R.J.; MARX, R.E. Tissue Engineering. Quintessence Publishing Co, Inc.

JINGUISHI, S.; AZUMA, Y.; ITO, M.; HARADA, Y.; TAKAGI, H.; OHTA, T.; KOMORIYA, K. (1998). Effects of non-invasive pulsed low-intensity ultrasound on rat femoral fracture. Proceedings of the Third World Congress of Biomechanics, 175b.

JUNQUEIRA, L. C.; CARNEIRO, J. (1995). Histologia. $8^{\circ}$ ed. Rio de Janeiro: Guanabara Koogan.

KENWRIGHT, J.; GOODSHIP, A. E. (1989). Controlled mechanical stimulation in the treatment of tibial fractures. Clin. Orthop. 241: 36-47.

KRISTIANSEN, T. K.; RYABY J. P.; McCABE, J.; FREY, J. J.; ROE, L. R. (1997). Accelerated healing of distal radial fractures with the use of specific low-intensity ultrasound. Journal of Bone and Joint Surgery. 79-A (7), p. 961-973. 
KOKUBO, T.; MATSUI, N.; FUJIOKA, H.; TSUNODA, M.; MIZUNO, K. (1999). Low-intensity pulsed ultrasound exposure increases prostaglandin E2 production via the induction of cyclooxygenase- 2 mRNA in mouse osteoblasts. Biochemical and Biophysical Research Communications, v. 256, p. 284-287.

MAYR, E.; RUTER, A. (1998). Fracture healing and ultrasound - Basics and first experience, in Actualités en Biomatériau, ed. By Mainard, D.; Merle, M.; Delgoutte, J. P.; Louis, J. P. Editions Romillat, (3): 355-360.

MARCUS, R.; FELDMAN, D.; KELSEY, J. (1995). Osteoporosis. San Diego: Academic Press.

MARTIN, T. J.; FINDLAY, D. M.; HEATH, J. K.; Ng. K. W. (1993). Osteoblasts: differentiation and function. In: MUNDY, G. R. \& MARTIN, T. J. Physiology and pharmacology of bone. Berlin: Springer-Verlag, p.149-183.

MARTIN, R. B. (2000). Toward a unifying theory of bone remodeling. Bone, vol. 26, n. 1, p. 1-6.

MEANI, E.; ROMANO, C. L. (1997). Low-intensity pulsed ultrasound for the treatment of septic nonunion. Third Congress of the European Federation of National associations of Orthopaedics and Traumatology, Barcelona.

MORO, C. A. (1992). Fixação externa com grau de flexibilidade variável. Desenvolvimento do aparelho e da metodologia de utilização. 78p. Dissertação (Mestrado)- Faculdade de Medicina de Ribeirão Preto, Universidade de São Paulo.

MUNDY, G. R. (1999). Cellular and molecular regulation of bone turnover. Bone, vol. 24 , n. 55 , p. $355-385$.

MÜLLER, M.E. et al.(1991). Manual of internal fixator. 3.ed Berlin. Springer.

NARUSE, K.; MIKUNI-TAKAGAKI, Y.; AZUMA, Y. et al. (2000). Anabolic response of mouse-marrow-derived stromal cell clone ST2 cells to low-intensity pulsed ultrasound. Biochemical and Biophysical Research Communications, v. 268, p. 216220 .

NOBLE, B. S.; REEVE, J.(2000). Osteocyte function, osteocyte death and bone fracture resistance. Mol cell endocrinol, vol. 159, p. 7-13.

NUSSBAUM, E. (1998). The influence of ultrasound on healing tissue. J. Mand Ther., v. 11(2) p. 140-170.

OLIVEIRA FILHO, O. B. A. (2000). Influência da dinamização axial na consolidação da osteotomia na tíbia de carneiros tratadas com fixador externo unilateral uni-planar. Ribeirão Preto, 78 p. Dissertação (doutorado) -Faculdade de Medicina de Ribeirão Preto, Universidade de São Paulo. 
O’SUlliVAN, M. E.; BRONK, J. T.; CHAO, E. Y.; KELLY, P. J. (1994). Experimental study of the efect of weight bearing on fracture healing in the canine tibia. Clin. Orthop. 302: p. 273-283.

PACCOLA. C. A. J.; BELLEGARD, L. M.;ALMEIDA, I.L. (1985). O uso do fixador externo em clínica ortopédica: experiência de três anos no Hospital das Clínicas da Faculdade de Medicina de Ribeirão Preto-USP. Rev. Bras. Ortop.,v. 20, n. 2, p. 41-7.

PARK, S. H.; O'CONNOR, K.; MCKELLOP, H.; SARMIENTO, A. (1998). The influence of active shear or compressive motion on fracture-healing. J. Bone Joint Surg. 80-A(6): 868-878.

PILLA, A.A.; MONT, M.A.; NASSER, P. R.; KHAN, A. S.; FIGUEIREDO, M.; KAUFMAN, J.J.; SIFFERT, R.S. (1990). Non-invasive low-intensity pulsed ultrasound accelerates bone healing in the rabbit.J. Orthop. Trauma., v. 4, p. 246-253.

PILLA, A.A.; MONT, M.A.; NASSER, P. R.; KHAN, A. S.; FIGUEIREDO, M.; KAUFMAN, J.J.; SIFFERT, R.S.; ALVES J. M.; RYABY J. T.; KLEIN M. (1991). Acceleration of bone repair by pulsed sine wave ultrasound: animal, clinical and mechanistic studies. In: BRIGHTON, C.T.; POLLACK, S. R. eds. Electromagnetics in Medicine and Biology, San Francisco Press, Inc, San Francisco, p. 331- 341.

POLLAK, A. N.; ZIRAN, B. H. (2000). Princípios de Fixação Externa, In: BROWNER, B. D.; LEVINE, A. M.; JUPITER, J. B.; TRAFTON, P.G. Traumatismo do Sistema Musculoesquelético. Cap. 11, p.267-286.

QUARLES, L. D. (1977). Cation sensingreceptors in bone: a novel paradigm for regulating bone remodeling? J Bone Min Res, vol. 12, n. 12, p. 1971-1974.

RAMOS, M. R. F.; ROTBANDE.I. S; SHEHATA, I. (2000). Fixador externo efeito mola. Rev. Bras. Ortop., v. 35, n1/2, p. 23-8.

RAWOOL, N. W.; GOLDBERG, B. B.; FORSBERG, F.; WINDER, A. A.; TALISH, R. J.; HUME, E. (1997). Power doppler assessment of vascular changes during fracture treatment with low-intensity ultrasound. Radiological Society of North America, paper \# 1185, november 30 - December 5.

RYABY, J. T.; MATTHEW, J.; PILLA, A. A. (1991). Low-intensity pulsed ultrasound modulates adenylate cyclase activity and trasnforming growth factor beta synthesis. In: BRIGHTON, C. T.; POLLACK, S. R. eds. Electromagnetics in Medicine and Biology, San Francisco Press, Inc, San Francisco, p. 95-100.

RYABY, J. T.; MATTHEW, J.; ALVES P. D. ( 1992). Low-intensity pulsed affects adenylate cyclase and TGF-* synthesis in osteoblastic cells, Transactions of the $\mathbf{3 8}^{\text {th }}$ Annual Meeting, Orthopaedic Research Society, Washington DC, USA, February.

ROLLAND, E; SABOURIN, F. (1998). Consolidación ósea y rehabilitación. Encycl. Méd. Quir. p. 26-208-A-10, 10 p. 
ROSS, M. H. ( 1993). Histologia Texto e Atlas. $2^{\circ}$ ed. São Paulo: Médico Panamericana.

ROTBANDE. I. S.; RAMOS, M.R.F. (2000). Atualização em fixação externa: conceitos e revisão Rev. Bras. Ortop., v.35, n. 4, p. 103-7.

RUEDI, T. P.; MURPHY, W.M. (2000). AO Principles of Fracture Management. New York. Thieme. Cap. 1, p. 7-15.

SCHENK, R. K. (2000). Biologia da Reparação das fraturas. In: BROWNER, B. D.; LEVINE, A. M.; JUPITER, J. B.; TRAFTON, P.G. Traumatismo do Sistema Musculoesquelético. Cap. 2, p. 33-78.

SCHÖDER, H. A. et al. (1986). Fractures of the shaft on that tibia treat with Hoffmann external fixation. Arch . Orthop. Trauma Surg., v. 105, p. 28-30.

SILVA, O. L. (1987). Estudo do mecanismo de ação do ultra-som na estimulação do crescimento ósseo. São Carlos, 209p, Dissertação (mestrado)- EESC - Universidade de São Paulo - USP.

SØGAARD, C. H.; DANIELSEN, C. C.; THOLING, E. B.; MOSEKILDE, L. (1994). Long-term exercise of young and adult female rats: effect on femoral neck biomechanical competence and bone structure. J Bone Min Res, vol. 9, n. 3, p. 409416.

SOUZA, S.A. (1982). Ensaios Mecânicos de Materiais Metálicos. 5aed. São Paulo, Edgard Biücker, 286p.

STRAUSS, E.; OPPENHEIM, W.; PETRUCELLI, R. (1996). Accelerated fracture healing with pulsed low-intensity ultrasound, Final Programme of the $\mathbf{2 0}^{\text {th }}$ World Congress SICOT, august 18-23, Amesterdam, p. 538-539.

TAKIKAWA, S. et al. (2001). Low-intensity pulsed ultrasound initiates bone healing in rat nonunion fracture model. Journal of Ultrasound Medicine, n. 20, p. 197-205.

TANZER, M.; HARVEY, E.; KAY, A.; MORTON, P.; BOBYN, J. D. (1996). The effect of non-invasive low-intensity ultrasound on bone growth into porous coated implants. Journal of Orthop. Research, v. 14, p. 901-906.

TAVAROLI, M.; EVANS, J. A. (1992). The effect of bone struture on ultrasonic attenuation and velocity ultrasonics, J. orthop. Res, V. 6, p. 389-395.

TER HAAR, G. (1987). Basic physics on therapeutic ultrasound. Physiotherapy 73 (3): 110-113, mar.

TERJESEN, T. (1984). Bone healing after metal plate fixation and external fixation of the osteotomized rabbit tibia. Acta Orthop Scand 55: 69-77. 
TRELLES, M.A.; MAYAYO, E. (1990). Bone fracture consolidates faster with lowpower laser. Laser in Surgery and medicine, v.7, p. 36-45.

TUREK, S. (1991). Ortopedia Princípios e sua aplicação. $4^{\circ}$ ed. São Paulo: Manole.

TURNER, C. H.; FORWOOD, M. R.; RHO, J. Y.; YOSHIKAWA, T. (1994). Mechanical loading thresholds for lamellar and woven bone formation. J Bone Min Res, vol.9, n.1, p. 87-97.

TURNER, C. H.; OWAN, I.; TAKANO, Y. (1995). Mechanotransduction in bone: role of a strain rate. Am J Physiol (Endocrinol metabol 33): E 438- E 442.

VIDAL, J. (1983) External fixation: yesterday, today and tomorrow. Clin. Orthop., n. 180, p. 7-14.

WANG, S.; LEWALLEN, D. G.; BOLANDER M. E.; CHAO, E. Y. S.; ILSTRUP, D. M.; GREELEAF, J. F. (1994). Low-intensity ultrasound treatment increases strength in a rat femoral fracture model. Journal of Orthop. Research, v. 12, p. 40-47.

WOOLF, R. J.; DIXON, A. S. J. (1988). Um guia clínico - Osteoporose. London: Martin Dunitz.

YOUNG, S. R. et al,.( 1990). Effect of terapeutic ultrasound on the healing of fulltrickness excesed Skin lesions. Ultrasonics, v. 28, p. 175-180.

ZISKIN, M. C. ( 1989). Report on the Safety of the Therasonics Medical Systems (Exogen. Inc.) SAFHS Unit, model $2^{\mathrm{a}}$ PMA P900009, v. 3, VI. A.,- 234. 